\title{
IfLUÊNCIA DE BEBIDAS IngerIDAS ROTINEIRAMENTE POR Crianças na Microdureza do Esmalte De Dentes Decíduos:
}

\author{
Avaliação IN VITRO
}

Soraya Cheier Dib Gonçalves 


\title{
Soraya Cheier Dib GonçALVES
}

\section{INFLUÊNCIA DE BEBIDAS INGERIDAS ROTINEIRAMENTE POR CRIANÇAS NA MicroduREZA do ESMALTE de DENTES DeCÍDUOS: AvaliaÇÃO IN VITRO}

\author{
Dissertação apresentada à Faculdade de \\ Odontologia de Ribeirão Preto da \\ Universidade de São Paulo para a obtenção \\ do grau de Mestre em Odontopediatria.
}

Orientadora: Profa. Dra. Maria Cristina Borsatto

Ribeirão Preto - SP 


\section{Gonçalves, Soraya Cheier Dib}

Influência de bebidas rotineiramente ingeridas por crianças na microdureza do esmalte de dentes decíduos: avaliação in vitro. Ribeirão Preto, 2007.

66p.:il.; $30 \mathrm{~cm}$

Dissertação de Mestrado, apresentada à Faculdade de Odontologia de Ribeirão Preto/USP. Área de concentração: Odontopediatria.

Orientadora: Borsatto, Maria Cristina.

1. Erosão dental. 2. Esmalte dental. 3. Dentes decíduos. 


\section{Soraya Cheier Dib Gonçalves}

\section{INFLUÊNCIA DE BEBIDAS INGERIDAS ROTINEIRAMENTE POR CRIANÇAS NA MiCRODUREZA DO ESMALTE DE DeNTES DeCÍDUOS: AVALIAÇÃo IN VITRO}

Dissertação apresentada à Faculdade de Odontologia de Ribeirão Preto da Universidade de São Paulo para a obtenção do grau de Mestre em Odontopediatria.

Data da defesa:

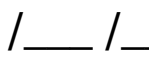

Banca Examinadora

Prof. Dr.

Julgamento assinatura

Prof. Dr.

Julgamento assinatura

Prof. Dr. Julgamento assinatura 


\section{DADOS CURRICULARES}

\section{SORA YA CHEIER DIB GONÇALVES}

Nascimento $\quad$ 04/03/1977 - Brasília - DF

Filiação

Aldimiro Gonçalves de Souza

Maria Lúcia Cheier Dib Gonçalves de Souza

1997-2001 Curso de Graduação

Faculdade de Odontologia da Universidade de

Uberaba - MG

2002 -2004 Especialização em Odontopediatria

Associação Odontológica de Ribeirão Preto/ SP

2005 -2007 Curso de Pós-Graduação em Odontopediatria, nível Mestrado da Faculdade de Odontologia de Ribeirão Preto da Universidade de São Paulo FORP/USP 
"A mente que se abre a uma nova idéia jamais voltará ao seu tamanho original" (A. Einstein) 


\section{Dedico este TrabalHo,}

Ao meu querido pai Aldimiro Gonçalves de Souza (in memorian) por me iluminar e proteger como um anjo da guarda. Pai, se hoje estou aqui é porque você ajudou a seguir a profissão que eu escolhi me apoiando sempre. Não tem palavras que possam expressar a minha eterna gratidão por tudo aquilo que você plantou em meu coração e minha mente. Obrigada.

À minha mãe, Maria Lúcia Dib, dona de uma cultura incrivel, por ter me ajudado a prosseguir meus estudos me incentivando em todos os sentidos. Sempre que penso que não vou conseguir algo, lembro daquilo que você me ensinou: "Não deixe seu sangue virar água"... e acho que não tenho deixado. Agradeço todos os dias por ter uma mãe tão sábia. Querida mãe, você para mim é exemplo de uma mulher inteligente. Espero ainda aprender muito com você. Obrigada me apoiar em um momento tão importante.

Ao meu esposo Carlos Américo Alves, pessoa que mais amo e admiro. Você é exemplo de dedicação, perseverança, garra, competência, inteligência e simplicidade. Durante esses anos você foi a pessoa que mais me apoiou, compreendeu e incentivou. Obrigada por tudo, sempre.

Aos meus irmãos Rossana e Neto, pelo carinho que vocês têm por mim e por torcerem por tudo o que eu faço.

Aos meus queridos sobrinhos Bruno e Victor, duas crianças lindas as quais não tenho palavras para expressar o meu amor.

À Dinda Lázara Celina por ser minha segunda mãe. Pessoa muito especial, a qual eu devo muito. Você é exemplo de bondade e carinho que não tem fim. Obrigada pelo amor de mãe que você sempre teve por mim.

À Silvani dos Reis por ser como uma irmã mais velha. Você cuida de todos nós com muito carinho e dedicação que eu nunca vi em toda a minha vida. Sempre serei eternamente grata a você.

A Deus, pela minha família, base de tudo na minha vida. 


\section{Agradecimentos}

\section{À Profa Dra Maria Cristina Borsatto (minha orientadora):}

O que mais me encanta em você, Cris, é a sua serenidade, sua incrivel capacidade de nos acalmar nos momentos mais dificeis. Tenho muito orgulho de ter tido a oportunidade de conviver com uma pessoa com esse dom. Dona de uma inteligência incrivel e muito senso de humor, você acolhe seus orientados de forma inigualâvel. Admiro a amizade e o carinho que você tem com seus alunos. É um privilégio ter você como orientadora. Serei eternamente grata por todos seus ensinamentos de mestre e de ser humano.

Sua "desorientada" Soraya.

À Profa Dra Regina Guenka Palma Dibb, sem a qual não seria possível a realização deste trabalho. Obrigada pela paciência e por ter contribuído de forma tão importante em todas as etapas desta dissertação. Meus sinceros agradecimentos.

À Carolina Paes Torres, por ter sido a precursora deste projeto na Odontopediatria desta faculdade. Por todas as dicas, meu muito obrigada.

Às colegas Carolina de Souza Guerra, Cristhiane Ristum Bagatin Rossi, Cristiane Thomaz Rocha, Iza Peixoto, Jaciara Miranda Gomes da Silva, Maria Stella Gaspar Gomes Raffaine, Patrícia Maria Monteiro, Patrícia Fernandes Motta, Regina Aparecida Segatto Saiani, Thaís Helena Andreolli do Amaral: "As pessoas entram na nossa vida por acaso, mas não é por acaso que elas permanecem". Obrigada a cada uma de vocês que entraram e permaneceram na minha vida de modo especial.

Às colegas Jaciara Gomes Miranda da Silva e Marta Maria Martins Giamatei Contente, minhas "colegas de orientadora". Foi muito bom este período em que convivemos. Obrigada pela parceria nos trabalhos e no dia a dia. 
Ao Richard Honorato Oliveira, pessoa muito especial, de uma bondade nata, colega desde a graduação, mas só agora descobri seu talento artístico. Obrigada por ter contribuído na parte grăfica deste trabalho.

Aos alunos do doutorado Francisco Wanderlei Garcia, Valéria Pontelli Navarro, Alexandra Mussolino de Queiroz, Raquel Assed Bezerra da Silva especialmente à Soraia Monique Fiorati Aguiar que se empenhou em ajudar nos momentos em que eu mais precisei e à Maria Angêlica Hueb de Menezes, a qual me instruiu desde a minha graduação na busca do meu caminho profissional.

Aos colegas Fumiu Matoba Júnior, Andréa Soares de Oliveira Ortolan e Adriana Sasso Stuani pela amizade e convivência.

À Michelle Alexandra Chinelatti, pela ajuda no laboratório.

Aos docentes do Departamento de Clínica Infantil, Odontologia Preventiva e Social da Faculdade de Odontologia de Ribeirão Preto da Universidade de São Paulo: Profa Dra Sada Assed, Profa Dra Aldevina Campos de Freitas; Profa Dra Alexandra Mussolino de Queiroz; Profa Dr ${ }^{a}$ Kranya Victoria Díaz Serrano; Profa Dra Léa Assed Bezerra da Silva; Profa Dra Maria Cristina Borsatto; Prof. Dr. Paulo Nelson Filho; Prof ${ }^{a} r^{a}$ Maria Conceição Pereira Saraiva; Prof Dra Maria Bernardete Sasso Stuani; Profa Dra Mirian Aiko Nakame Matsumoto; Prof. Dr. Adilson Thomazinho; Prof. Dr. José Tarcísio de Lima Ferreira e aos Professores associados: Prof. Dr. Mário Roberto Leonardo e Prof $\mathrm{Dr}^{\mathrm{a}}$ Isabel Yoko Ito. Tenho um carinho especial por cada um de vocês. Não tem preço nem palavras que possam agradecer o papel crucial que vocês desempenharam na minha formą̧ão.

Aos Professores, Pacientes e Funcionários da Clínica de Pacientes Portadores de Necessidades Especiais da Faculdade de Odontologia de Ribeirão Preto da Universidade de São Paulo, especialmente à Profa . Dra Aldevina Campos Freitas, exemplo de dedicação, carinho, amor e respeito com os pacientes e alunos. 
Aos funcionários do Departamento de Clínica Infantil, Odontologia Preventiva e Social da Faculdade de Odontologia de Ribeirão Preto da Universidade de São Paulo: Benedita Viana Rodrigues, Carmo Eurípedes Terra Barreto, Fátima Aparecida Jacinto Daniel, Fátima Aparecida Rizóli, Gisele Faria, Carolina Paes Torres, José Aparecido Neves do Nascimento, Kleber Barbosa Rita, Nadir das Dores Gardim Felício, Nilva Aparecida Afonso Ruggiero, Raquel Assed Bezerra da Silva, Rejane Gomes Cavalheiro Mazer, Renata Aparecida Fernandes Rodrigues e Vera Ribeiro do Nascimento.

A Gisele Faria, que muito contribuiu na minha formação. Obrigada por estender a mão sempre que precisei da sua ajuda.

À funcionária Benedita Viana Rodrigues: Impossível não gostar da Ditinha! Dona de um bom humor contagiante e uma bondade acolhedora. Exemplo de pessoa que ama o que faz. Obrigada pelo carinho.

Aos Funcionários Vera Ribeiro do Nascimento e José Aparecido Neves do Nascimento, por serem pessoas na qual eu sempre contei em tudo o que precisei. Vocês fazem toda a diferença. Obrigada pela boa vontade que vocês sempre tiveram comigo.

Aos alunos da nova turma de mestrado: Ana Paula Ramos B. da Silva, Cristina Bueno Brandão, Edélcio Garcia Júnior, Giselle de Ângelo Souza Leite, Lourdes Garcia Olmedo, Marcela Perdiza, Marta Maria Martins Giamatei Contente, Nury Teresa Valdez Quispe, Olívia Santos de Oliveira Verendo, Remberto Argandoña, Rodrigo Machado da Silva, Rosângela Morais Marques Sawan, Taiana de Melo dias, Vanessa da Rocha Bernardini por comparecerem às defesas das dissertações e teses desta faculdade, sempre aprendendo e prestigiando os colegas.

Às funcionárias da Seção de Pós-Graduação da Faculdade de Odontologia de Ribeirão Preto da Universidade de São Paulo: Isabel Cristina Galino Sola e Regiane Cristina Moi Sacilotto, pessoas competentes e prestativas. Muito Obrigada. 
Ao Departamento de Química da Faculdade de Filosofia Ciências e Letras da Universidade de São Paulo/ Campus Ribeirão Preto e ao funcionário Rodrigo Ferreira da Silva, pela disposição e paciência na elaboração das imagens da Microscopia Eletrônica de Varredura.

À FAPESP (FUNDAÇÃO DE AMPARO À PESQUISA DO ESTADO DE SÃO PAULO), pela concessão da bolsa de estudo e a cobertura financeira deste projeto. 


\title{
Resumo
}

\author{
Gonçalves, S.C.D. Influência de Bebidas Ingeridas Rotineiramente por Crianças na \\ Microdureza do Esmalte de Dentes Decíduos: Avaliação in vitro (dissertação). \\ Ribeirão Preto: FORP - Univ. de São Paulo, 2007.
}

O objetivo deste estudo foi avaliar, in vitro, a influência do refrigerante de limão $\left(\right.$ Sprite $^{\circledR}$ ), do suco à base de soja sabor maçã (Ades ${ }^{\circledR}$ ) e do suco de morango (Kapo ${ }^{\circledR}$ ), empregadas rotineiramente na alimentação de crianças na microdureza superficial e profunda do esmalte de dentes decíduos em função do tempo de exposição. Foram utilizadas quarenta coroas de incisivos decíduos humanos hígidos, acomodados em bases de acrílico mantendo as superfícies vestibulares expostas. Os conjuntos dente/base de acrílico foram impermeabilizados com esmalte cosmético, deixando exposta uma área de $3 \mathrm{~mm}$ de diâmetro na face vestibular, na qual foram realizadas as medidas de microdureza superficial Knoop (50 gf, 10 segundos e 5 endentações). Os espécimes foram divididos aleatoriamente em 4 grupos $(n=10)$, de acordo com as bebidas empregadas (Sprite ${ }^{\circledR}$, Ades $^{\circledR}$, Kapo ${ }^{\circledR}$ ) e controle (mantidos em saliva artificial). Os ciclos de imersão foram realizados sob agitação, durante 5 minutos, 3 vezes ao dia, com intervalos de 4 horas durante 60 dias. As medidas de microdureza superficial foram realizadas após 7, 15, 30, 45 e 60 dias. Obtidas as medidas superficiais, os espécimes foram cortados no sentido longitudinal, lixados e polidos para a avaliação das medidas de microdureza a 30, 60, 90, 120, 150, 200 e 300 $\mu$ m de profundidade em relação à superfície exposta das bebidas. Os dados da microdureza superficial e profunda foram analisados estatisticamente pelos testes ANOVA e Tukey. Foi realizada a microscopia eletrônica de varredura em 20 coroas de incisivos decíduos humanos hígidos submetidos ao mesmo protocolo de imersão dos espécimes utilizados para a análise de microdureza. Nos resultados da porcentagem de variação de microdureza superficial (\%VMS), observou-se que - Sprite ${ }^{\circledR}$ apresentou a maior variação de micro dureza superficial $(62,02 \%)$, sendo estatisticamente diferente do Kapo ${ }^{\circledR}$ morango $(49,05 \%)$ do Ades ${ }^{\circledR}$ maçã $(40,56 \%)$ e da saliva $(-11,31 \%)$. Houve perda progressiva da microdureza ao longo dos períodos estudados. Os resultados da microdureza em profundidade mostraram que houve diferença estatisticamente significante entre o refrigerante de limão $(117,98 \mathrm{KHN})$, o suco de maçã à base de soja (188,18 KHN) e o suco de morango (157.27 KHN). Apenas na profundidade de $300 \mu \mathrm{m}$ é que ocorreu semelhança entre as quatro soluções estudadas. Concluiu-se que todas as bebidas avaliadas alteraram a microdureza do esmalte de dentes decíduos tanto superficialmente quanto em profundidade. A alteração em profundidade foi evidente até $200 \mu \mathrm{m}$, sendo que o Sprite ${ }^{\circledR}$ alterou o esmalte de maneira mais intensa. Observou-se ainda que a alteração na microdureza do esmalte foi diretamente proporcional ao tempo de exposição a essas bebidas. As soluções deste estudo influenciaram negativamente a dureza do esmalte.

PALAVRAS - CHAVE: erosão dental; esmalte dental; dentes decíduos. 


\section{Abstract}

Gonçalves, S.C.D. Influence of Beverages Routinely Used in Children's Diet on the Enamel Microhardness of Primary Teeth: An in vitro evaluation (dissertation). Ribeirão Preto: FORP - Univ. of São Paulo, 2007.

The aim of this study was to assess, in vitro, the influence of a lemon soft drink $\left(\right.$ Sprite $^{\circledR}$ ), an apple soya juice (Ades ${ }^{\circledR}$ ) and a strawberry juice (Kapo ${ }^{\circledR}$ ) routinely utilized in children's diet on the superficial and deep microhardness of primary teeth enamel, as a function of the exposure time. Forty crowns of caries-free human primary incisors were included in acrylic bases, keeping the buccal surfaces exposed. The ensembles tooth/acrylic base were rendered waterproof by coating them with cosmetic nail varnish, leaving exposed a 3-mm area on the buccal surface, in which superficial Knoop microhardness measurements were performed (50 gf, $10 \mathrm{sec}$ and 5 indentations). The specimens were randomly assigned to 4 groups $(n=10)$, according to the beverages employed $\quad\left(\right.$ Sprite ${ }^{\circledR}$, Ades $^{\circledR}$, Kapo $\left.^{\circledR}\right)$ and the control group (kept in artificial saliva). The immersion cycles were performed under agitation for 5 minutes, 3 times a day, with 4 hours intervals, during a 60-day period. The superficial microhardness measurements were done after 7,15,30,45 and 60 days. Once the superficial measurements were performed, the specimens were longitudinally cut, ground and polished for the deep measurements to be accomplished. Microhardness measurements were done at $30,60,90,120,150,200$ e $300 \mu \mathrm{m}$ deep from the surface exposed to the beverages. Superficial and deep microhardness data were statistically analyzed using ANOVA and Tukey statistical tests. Scanning electron microscopy was performed in 20 crowns of caries-free human primary incisors submitted to the same imersion regimen as that of specimens utilized for microhardness testing. The results of superficial microhardness variation percentage (\%VMS) showed that Sprite ${ }^{\circledR}(62,02 \%)$ yielded the greatest microhardness, being statistically different from Kapo ${ }^{\circledR}(49,05 \%)$; $\operatorname{Ades}^{\circledR}(40,56 \%)$ and saliva $(-11,31 \%)$. There was a gradual and significant microhardness loss on superficial microhardness in all periods evaluated. The results of deep microhardness showed that there was statistically significant difference between the lemon soft drink (117, $98 \mathrm{KHN})$, apple soya juice $(188,18$ $\mathrm{KHN}$ ) and the strawberry juice (157.27 KHN). There was similarity between the beverages evaluated only at $300 \mu \mathrm{m}$ depth. It may be concluded that all beverages evaluated altered both the superficial and the deep microhardness of enamel of primary teeth. The alteration

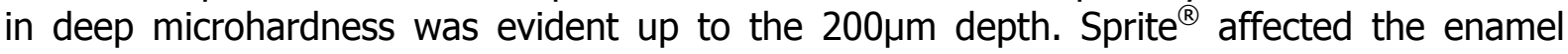
more aggressively. It was also observed that the alteration on the enamel microhardness was directly proportional to the time of exposure to the beverages. The beverages of the reported study presented a negative impact on the enamel surface and depth of primary teeth.

KEY WORDS: dental erosion; dental enamel; primary teeth. 


\section{SUMÁRIO}

1 INTRODUÇÃO

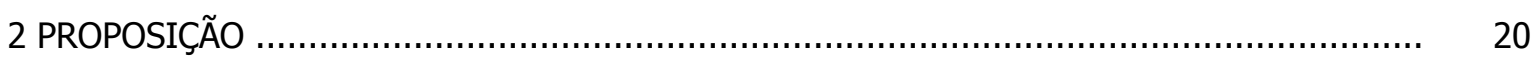

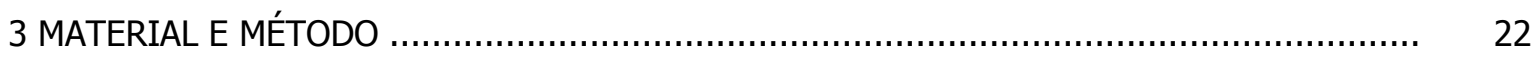

3.1 Preparo dos Espécimes de Esmalte............................................................... 23

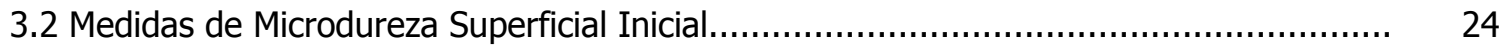

3.3 Ciclos de Imersão.............................................................................. 25

3.4 Avaliação da Microdureza Superficial................................................................ 27

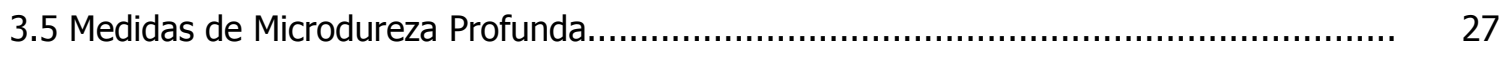

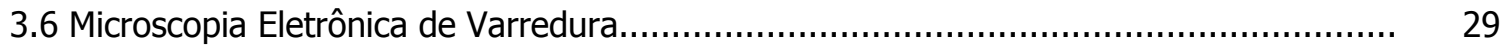

3.7 Análise dos Dados.............................................................................. 31

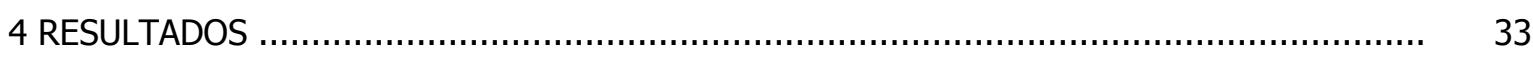

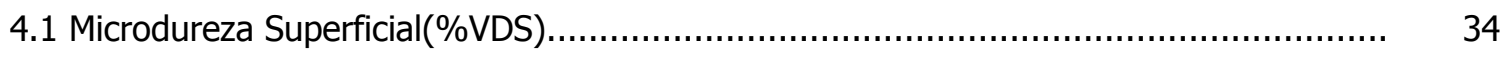

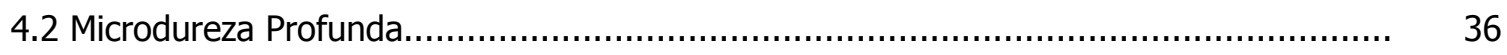

4.3 Microscopia Eletrônica de Varredura................................................................ 39

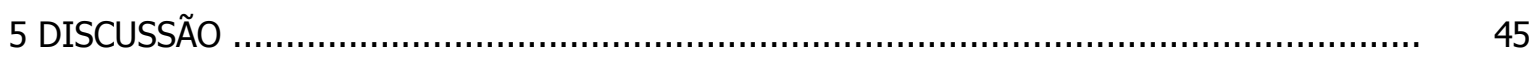

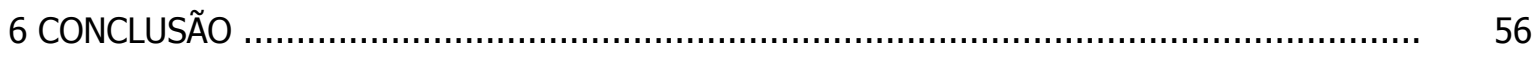

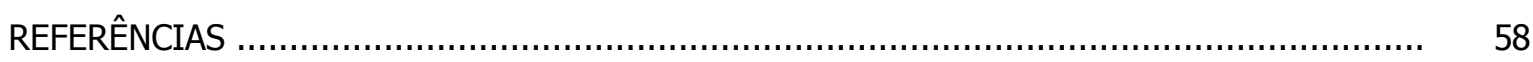

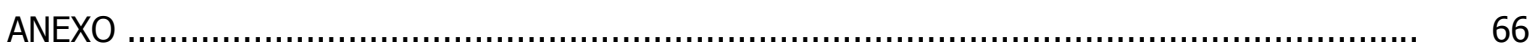




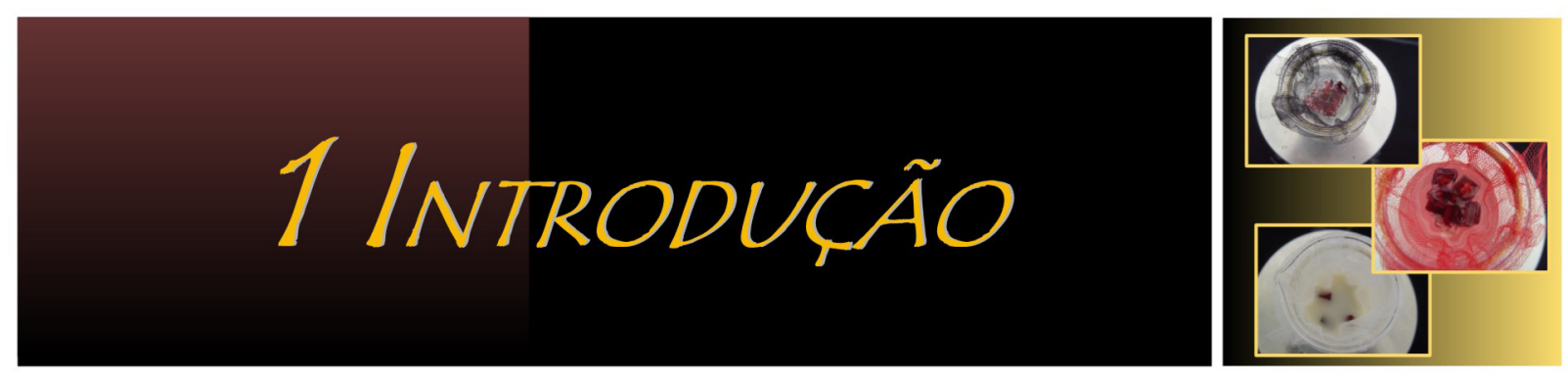




\section{INTRODUÇÃo}

Durante muitas décadas, a doença cárie foi considerada a principal responsável pela destruição da estrutura dentária. Atualmente, está ocorrendo um declínio de sua prevalência em nível mundial em função da aplicação dos vários métodos preventivos, principalmente, pela utilização dos fluoretos (Newbrun, 1992; Marthaler, 1996). Desse modo, tem-se observado outras formas destrutivas como o desgaste dentário, que é definido como sendo um processo multifatorial, cumulativo e irreversível quando muito acentuado (Lussi et al., 2000).

O desgaste dentário pode ser classificado em atrição, abrasão (Eccles, 1982); abfração (Bartlett e Shah, 2006) e erosão (Eccles, 1982). O diagnóstico dessas categorias é dificultado uma vez que os mecanismos de desgaste dental raramente agem sozinhos, pois existe uma interação entre eles (Addy e Shellis, 2006). Assim, atrição é definida como a perda fisiológica de esmalte, dentina, ou restauração decorrente de contatos dentários durante a mastigação, deglutição e fonação (Eccles, 1982; Litonjua et al., 2005). A abrasão é o desgaste patológico que ocorre por forças mecânicas não fisiológicas e pode estar associada com técnica de escovação incorreta, uso de dentifrício com quantidade excessiva de compostos abrasivos e objetos levados à boca como palito de dentes (Imfeld, 1996; Litonjua et al., 2005). As lesões por abfração surgem na presença de traumas oclusais, quando um excesso de carga incide sobre o dente e este não suporta o esforço, levando à deflexão da estrutura dentária e, em seqüência, há uma ruptura dos cristais na região cervical, formando a lesão. Apresentam-se como defeitos, geralmente em forma de cunha, limitando-se à área cervical dos dentes com término cavitário nítido (Rees, 2006).

A erosão dental é a conseqüência da perda superficial de tecidos dentais mineralizados promovida por processos químicos não envolvendo presença de bactérias (Zipkin e Mcclure, 1949; Eccles, 1982; Litonjua et al., 2003; Magalhães et al., 2007). 
Destaca-se pela diminuição do brilho, lesão arredondada e presença de uma faixa de esmalte que separa a área desmineralizada da gengiva marginal. A erosão na superfície oclusal provoca arredondamento das cúspides e formação de concavidades que podem expor a dentina. Em estágios avançados de erosão ocorrem extensas áreas de desmineralização nas superfícies palatinas dos dentes anteriores e superiores (Lussi et al.,1995).

Os ácidos promotores da erosão podem ter origem intrínseca ou extrínseca, sendo os intrínsecos, associados às doenças que provocam distúrbios gastrintestinais e produzem constante regurgitação como hipertireoidismo, bulimia e anorexia nervosa (Järvinen et al., 1988; Milosevic e Slade, 1989; Tylenda et al., 1991) e extrínsecos, provenientes da dieta como frutas cítricas, bebidas ácidas e vinagres; medicamentos (vitamina C, ácido acetil salicílico, ácido clorídrico); água flavorizada (Brown et al., 2007); fontes industriais como a exposição a contaminantes ácidos a que estão sujeitos operários em seus ambientes de trabalho (Lussi et al., 2000); praticantes de natação, expostos constantemente ao cloro das piscinas (Scheper et al., 2005); enxagatórios bucais com formulações que contém cloreto de sódio acidificado (Pontefract et al., 2001) agentes de clareamento dental que contém ácido cítrico (Zantner et al., 2007).

Dentre os fatores etiológicos mais estudados na erosão dental, destacam-se os ácidos provenientes da dieta, em função do alto consumo de bebidas ácidas que está ocorrendo atualmente. A ingestão de líquidos na dieta tem sido cada vez mais recomendada e, isto se acentua nos países de clima quente (Lussi et al, 1995; Brown et al., 2007). A grande oferta de bebidas no comércio e a diversidade de frutas ácidas fazem com que algumas delas estejam relacionadas ao desenvolvimento das lesões por erosão.

Vários métodos têm sido utilizados, em estudos laboratoriais, para a quantificação da erosão dental, tais como, a análise da dureza superficial, que pode ser realizada por testes de microdureza (Maupomé et al., 1998, Maupomé et al., 1999) ou 
nanoedentação (Mahoney et al., 2003; Barbour et al., 2003; Lippert et al., 2004), perfilometria (Hughes et al., 1999; Hughes et al., 2000; West et al., 1999; West et al., 2003; Kitchens e Owens, 2007), microrradiografia (Hall et al., 1997; Anderson et al., 1999), análise química (Grobler e Van der Horst, 1982; Margolis et al., 1999), microscopia eletrônica de varredura (Meurman e Frank, 1991; Maia e Modesto, 1996; Eisenburger et al., 2004), microscopia de força atômica (Watari, 1999) e a técnica de fluorescência pela indução de luz (Pretty et al., 2003). No entanto, os testes de microdureza são os mais utilizados em função da simplicidade, rapidez e precisão da técnica, além de apresentar um custo mais acessível quando comparado aos demais métodos (Barbour e Rees 2004). Aliada aos testes de microdureza deve-se salientar a importância da realização da microscopia eletrônica de varredura, que por ser um método de análise qualitativo, contribui para a confirmação dos resultados obtidos na avaliação da dureza superficial.

Um estudo de Järvinen et al.,(1991) demonstrou que a ingestão de frutas cítricas, mais que duas vezes ao dia, aumenta o risco de lesões por erosão em 37 vezes. Riscos semelhantes parecem ocorrer com a ingestão de vinagre de maçã (10 vezes maior), bebidas esportivas ( 4 vezes maior) e refrigerantes (4 vezes maior), quando consumidas diariamente. A perda de estrutura dental por erosão pode ser de, aproximadamente, $1 \mu \mathrm{m}$ no décimo segundo dia após a ingestão de bebidas ácidas (Touyz, 1994). Estudo de Larsen (2001) verificou que o valor médio do $\mathrm{pH}$ do refrigerante de limão é 2,8 e, estudando in vitro a erosão provocada por essa bebida, entre outras, concluiu que todos os produtos testados são potencialmente erosivos, sendo que o refrigerante de limão causou as maiores perdas de cálcio e fosfato inorgânico. Da mesma forma, Lussi et al. (2000) analisaram a microdureza Knoop do esmalte de dentes decíduos e permanentes após uma única imersão durante três minutos, em diferentes bebidas e observaram que as menores medidas de microdureza foram aquelas nas quais os dentes eram submetidos ao Sprite ${ }^{\circledR}$. Ainda neste trabalho, 
mostraram que os dentes decíduos não foram mais susceptíveis à erosão do que os dentes permanentes.

No entanto, Amaechi et al., (1999), Hunter et al. (2000) e Johansson et al.,(2001), ao avaliarem as duas dentições, observaram que, comparativamente, os dentes decíduos apresentaram um maior grau de erosão do esmalte em relação aos dentes permanentes.

Alguns estudos in vitro avaliando o potencial erosivo de bebidas ácidas no esmalte dentário têm sido realizados em dentes bovinos ou de ratos (Rytoma, 1988; Sorvari, 1989) os quais apresentam diferenças estruturais e morfológicas quando comparados aos dentes humanos (Seow e Thong,2005).

Muitos autores relataram a ocorrência do processo de erosão em dentes permanentes (Bjorvatn, 1982; Van Herpen et al., 1986; Lussi et al., 1993; Lewinstein et al., 1993; Grobler et al., 1994; Lussi et al., 1995; Yu et al., 1995; Maupomé et al., 1998; Sela et al., 1998; Gimalia et al., 1999; Mahoney et al., 2003). Porém, mais informações sobre a prevalência e patogênese da erosão em dentes decíduos são necessárias, pois existem diferenças micro-estruturais entre dentes decíduos e permanentes que devem ser consideradas, sendo os dentes decíduos mais porosos e menos mineralizados (Lippert et al., 2004) apresentando um arranjo diferente dos prismas de esmalte (Wilson e Beynon, 1989). Além disso, o consumo de bebidas ácidas por crianças apresentando dentição decídua ou mista é freqüente, e a ocorrência de lesões erosivas nesses dentes demonstra que os pais devem ser alertados sobre essa patogenia, tanto quanto vêm sendo conscientizados sobre a prevenção da doença cárie. A erosão dental que acomete essas crianças, mesmo que de forma branda, serve de alerta para a fase posterior da dentição permanente (Johansson et al., 2001; Torres, 2005).

Neste sentido, Torres (2005) avaliou a influência de uma bebida à base de cola e outra à base de soja (sabor laranja), na microdureza superficial e profunda de dentes 
decíduos, em função do tempo de exposição, no qual demonstrou que o refrigerante a base de cola e o suco de laranja à base de soja alteraram a dureza do esmalte dos dentes decíduos tanto superficialmente, quanto em profundidade, sendo que a Coca-cola ${ }^{\circledR}$ afetou o esmalte de maneira mais agressiva que o suco de laranja.

Desta forma, a literatura mostra que assim como em dentes permanentes, a exposição freqüente a bebidas ácidas pode resultar em erosão dental também em dentes decíduos. Apesar disso, estudos envolvendo dentes decíduos são escassos e, muitas vezes, controversos (Grando et al, 1996; Milosevich et al., 1997; Lussi et al., 2000; Lippert et al., 2004) tornando-se necessária a implementação de estudos avaliando este substrato. 
2 PROPOSICÃO

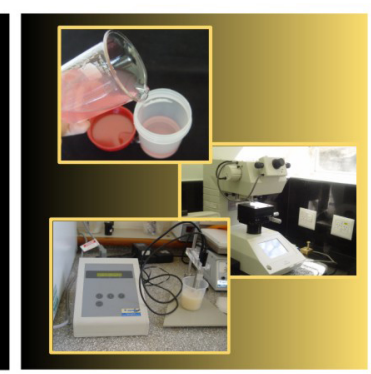




\section{Proposição}

Os objetivos deste trabalho foram avaliar a influência de três bebidas ingeridas rotineiramente por crianças na microdureza do esmalte de dentes decíduos quanto à microdureza superficial e profunda, em função do tempo de exposição. E avaliar qualitativamente, por meio de microscopia eletrônica de varredura as alterações superficiais do esmalte após a imersão dos dentes nas diferentes bebidas em função do tempo de exposição. 
3 Materiale

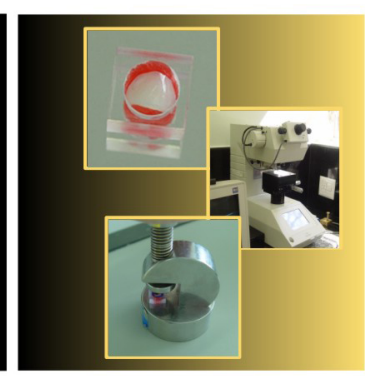




\section{Material e Método}

O presente estudo foi inicialmente submetido à apreciação pelo Comitê de Ética em Pesquisa da Faculdade de Odontologia de Ribeirão Preto da Universidade de São Paulo, processo número 2007.1.1079.58.6, recebendo parecer favorável (Anexo A).

\subsection{PRePaRo dos EsPÉCIMES De ESMALTE}

Foram selecionados 60 incisivos decíduos humanos hígidos extraídos, em Banco de Dentes Humanos da Faculdade de Odontologia de Ribeirão Preto da Universidade de São Paulo. Os dentes receberam profilaxia com pasta de pedra pomes e água e escova de Robinson, montada em micromotor, em baixa rotação, seguida do exame visual, com o auxílio de uma sonda exploradora, em estereomicroscópio (Nikon Inc. Instrument Group, Melville, NY 11747, USA), com aumento de 10X, descartando-se aqueles com trincas, fraturas, lesões de cárie ou anomalias de estrutura que pudessem comprometer os resultados.

Os dentes tiveram as raízes (quando presentes) seccionadas, com disco diamantado adaptado em máquina de corte (Miniton, Struers A/S, Copenhagen, DK-2610, Denmark), sob refrigeração, na porção cervical e as superfícies palatinas foram desgastadas, com ponta diamantada 1092 (KG Sorensen, Agerkov, Dinamarca) em alta-rotação (Silent MRS 400- Dabi Atlante, Ribeirão Preto-SP, Brasil), para melhor adaptação do dente à base de plexiglass, com dimensões de $1 \mathrm{~cm} \times 1 \mathrm{~cm} \times 0,3 \mathrm{~cm}$ e um orifício central de $0,7 \mathrm{~cm}$ de diâmetro.

Nessas bases foram acomodadas as coroas sobre uma pequena quantidade de cera utilidade, de forma que as superfícies vestibulares ficassem expostas.

Com o auxílio de um paralelômetro (ElQuip, São Carlos-SP, Brasil) a face vestibular foi nivelada de forma a deixar a região mais plana do dente paralela à placa, pois 
é essencial para a realização das medidas de microdureza que a área a ser trabalhada esteja plana.

Em seguida, os dentes foram fixados com cera para escultura (Kota Ind. E Com. Ltda, São Paulo, Brasil), aquecida em gotejador elétrico (Guelfi Equipamentos, Ribeirão Preto-SP, Brasil).

Na porção mais incisal e plana da superfície vestibular da coroa foi colocada uma fita adesiva (Scotch, 3M do Brasil Ltda, Sumaré, SP) de forma circular, com $3 \mathrm{~mm}$ de diâmetro, confeccionado com um perfurador modificado, com a finalidade de delimitar a área a ser exposta às soluções .

Os conjuntos dente-matriz de plexiglass foram impermeabilizados com duas camadas de esmalte cosmético (Colorama Maybelline - Ultra duração, Cosbra Cosméticos Ltda, São Paulo, SP) e após a completa secagem, as fitas adesivas, em forma de círculo, foram removidas para deixarem expostas somente as áreas em esmalte, previamente delimitadas.

Os espécimes foram mantidos em água deionizada a $\pm 4^{\circ} \mathrm{C}$ até $\mathrm{o}$ início dos ciclos de imersão. Vinte e quatro horas antes da medida de microdureza inicial foram imersos em saliva artificial (Laboratório Ciências farmacêuticas, Faculdade de Ciências Farmacêuticas da Universidade de São Paulo, Ribeirão Preto-SP, Brasil) e mantidos em estufa a $37^{\circ} \mathrm{C}$ (Olidef $\mathrm{CZ}$, Indústria e Comércio de Aparelhos Hospitalares Ltda, Ribeirão Preto-SP, Brasil).

\subsection{MEDIDAS DE MICRODUREZA SUPERFICIAL INICIAL}

A microdureza superficial inicial do esmalte foi avaliada utilizando-se um microdurômetro (HMV-2000/ Shimadzu Corporation, Japan). Foi utilizado um penetrador diamantado piramidal tipo Knoop, com carga estática de 50 gf, aplicada durante 10 segundos. Foram feitas 5 endentações aleatoriamente, distribuídas na área delimitada. Foi 
obtido o valor médio da microdureza de cada dente, sendo desprezados aqueles que apresentaram um valor $10 \%$ acima ou abaixo da média de todos os espécimes. Desta forma, das 60 coroas previamente obtidas, 40 foram selecionadas para o teste de microdureza e 20 foram selecionadas para a microscopia eletrônica de varredura.

Para medir as endentações realizadas, duas marcas que aparecem no visor do microdurômetro foram sobrepostas aos vértices agudos do losango correspondente à endentação, determinando o comprimento da maior diagonal e, conseqüentemente, o valor de dureza Knoop calculado automaticamente pelo software do equipamento.

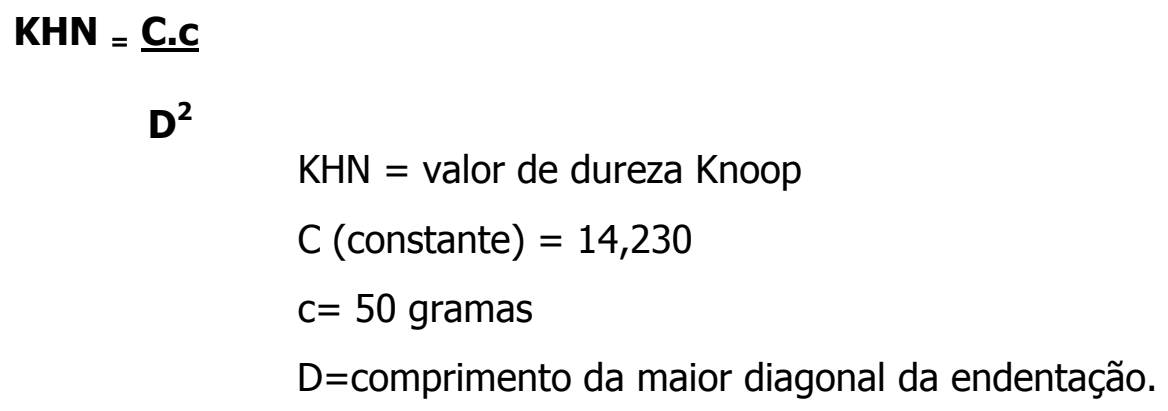

\subsection{CICLOS DE IMERSÃO}

Foram utilizados três produtos disponíveis comercialmente: um refrigerante à base de limão, contendo em sua composição química, ácido cítrico (Sprite ${ }^{\circledR}$, Cia Fluminense de Refrigerantes, Porto Real, RJ), um suco de maçã à base de soja, composto de ácido cítrico (Ades ${ }^{\circledR}$ Frutas Unilever Bestfoods Brasil Ltda, Pouso-Alegre /MG, Brasil) e um suco de morango, composto de ácido cítrico e ácido málico (Kapo ${ }^{\circledR}$ Companhia de Bebidas Ipiranga, Ribeirão Preto/SP; Indústria Brasileira de Bebidas S.A. Jundiaí/SP).

$\mathrm{O}$ pH das soluções foi obtido através de um pH-metro digital (Analion ${ }^{\circledR}$ AN2000 Microprocessado, Ribeirão Preto-SP, Brasil), sendo de 2,98 para o refrigerante de limão; 4,06 para o suco de maçã à base de soja e 3,78 para o suco de morango. As bebidas encontravam-se à temperatura de $\pm 4^{\circ} \mathrm{C}$. 
Os corpos-de-prova foram divididos, aleatoriamente, em 4 grupos $(n=10)$, de acordo com as soluções a serem testadas e um grupo controle, no qual os espécimes foram mantidos em saliva artificial. A tabela 1 apresenta a composição das soluções avaliadas:

Tabela 1- Composição das soluções utilizadas

\begin{tabular}{|c|c|}
\hline SOLUÇÃO & COMPOSIÇÃO \\
\hline SPRITE $^{\circledR}$ & $\begin{array}{l}\text { Água gaseificada } \\
\text { Açúcar } \\
\text { Suco natural de limão (2,5\%), } \\
\text { Acidulante INS } 330 \text { (ácido cítrico) } \\
\text { Conservante INS } 221 \\
\text { Aroma natural }\end{array}$ \\
\hline ADES $^{\circledR}$ MAÇÃ & $\begin{array}{l}\text { Água } \\
\text { Açúcar } \\
\text { Extrato de soja } \\
\text { Suco concentrado de maçã } \\
\text { Vitamina C } \\
\text { Estabilizante } \\
\text { Pectina cítrica } \\
\text { Acidulante ácido cítrico } \\
\text { Aromatizante }\end{array}$ \\
\hline KAPO ${ }^{\circledR}$ MORANGO & $\begin{array}{l}\text { Água } \\
\text { Açúcar } \\
\text { Suco de morango } \\
\text { Cálcio } \\
\text { Acidulantes INS } 330 \text { (ácido cítrico) } \\
\text { Acidulante INS } 296 \text { (ácido málico) } \\
\text { Corante natural INS } 120 \\
\text { Estabilizantes INS } 412,444 \text { e } 445 \\
\text { Aroma sintético idêntico ao natural }\end{array}$ \\
\hline SALIVA ARTIFICIAL & $\begin{array}{l}\text { Fosfato diácido de potássio } \\
\text { Fosfato dibásico de potássio } \\
\text { Cloreto de potássio } \\
\text { Cloreto de sódio } \\
\text { Cloreto de magnésio } \\
\text { Cloreto de cálcio } \\
\text { Fluoreto de sódio } \\
\text { Sorbitol } 70 \% \\
\text { Aromatizante e corante } \\
\text { Conservantes } \\
\text { Nipagin } 9 \% / \text { Nipasol } 1 \% \\
\text { Benzoato de sódio } 10 \% \\
\text { Hidroxietilcelulose (natrosol) } \\
\text { Água q.s.p. }\end{array}$ \\
\hline
\end{tabular}

Após a realização da medida de microdureza inicial, foram realizados os ciclos da seguinte forma: os corpos-de-prova foram imersos em $75 \mathrm{~mL}$ da solução, durante 5 
minutos, sob agitação em um agitador magnético (Fanen, São Paulo-SP, Brasil), três vezes ao dia, com intervalos de 4 horas entre cada ciclo de imersão/agitação, durante 60 dias. Após cada imersão/agitação, os espécimes foram lavados em água destilada, secos com gaze e mantidos em $15 \mathrm{~mL}$ de saliva artificial a $37^{\circ} \mathrm{C}$, até o próximo procedimento de imersão/agitação. No grupo controle, os espécimes permaneceram em saliva artificial durante 60 dias. Foram realizadas trocas diárias de saliva artificial em todos os grupos e estes foram mantidos em estufa a $37^{\circ} \mathrm{C}$.

As soluções que foram utilizadas durante a imersão/agitação estavam a $\pm 4^{\circ} \mathrm{C}$, correspondendo à temperatura que normalmente são ingeridas. $\mathrm{O}$ refrigerante à base de limão, após cada imersão/agitação foi desprezado, sendo que os sucos de maçã e morango foram descartados diariamente, ou seja, após 3 procedimentos de imersão/agitação.

As medidas de microdureza superficial foram realizadas $7,15,30,45$ e 60 dias da repetição contínua e sistemática destes ciclos diários.

\subsection{AVALIAÇÃO DA MICRODUREZA SUPERFICIAL}

Após a obtenção das medidas, nos diferentes períodos, e utilizando os mesmos parâmetros (50gf, 10 seg., 5 endentações) foi realizado o cálculo da porcentagem de variação de dureza superficial (\%VDS) de acordo com a fórmula:

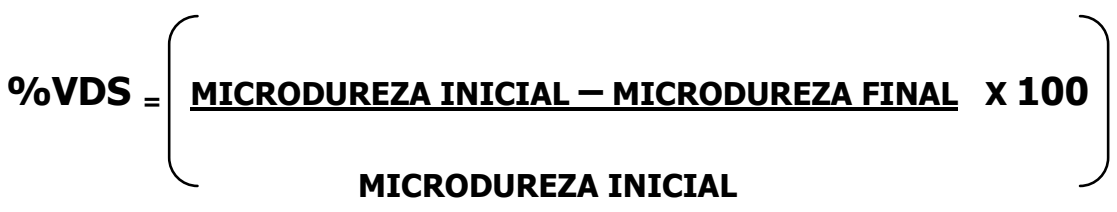

\subsection{MedidAs de Microdureza PRofunda}

Após 60 dias, a microdureza profunda do esmalte foi avaliada utilizando-se os mesmos parâmetros utilizados para as medidas de microdureza superficial. 
Os conjuntos dente-matriz de plexiglass foram cortados longitudinalmente, no sentido vestíbulo-lingual, com um disco de diamante montado em uma máquina de corte (Miniton - Struers A/S, DK-2610, Denmark), de modo a obter duas seç̧ões para cada dente.

As secções foram lixadas em uma politriz (Politiz DP-9U2, Struesrs, A/S, Copenhagen, DK-2610, Denmark) com lixas de carbureto de silício (Norton/Saint-Gobain Abrasivos Ltda, Guarulhos-SP, 07111-150, Brasil) nas granulações de 600, 1200, 2000 e polidas com discos de feltros (Buehler, Illinois, EUA) e pasta de alumina (Struers A/S, Copenhagen, Dinamarca) a fim de se obter uma superfície polida e lisa para a realização das medidas de microdureza profunda.

As medidas foram obtidas a 30, 60, 90, 120, 150, 200 e $300 \mu \mathrm{m}$ de profundidade, em relação à superfície exposta às bebidas testadas (Figura 1).

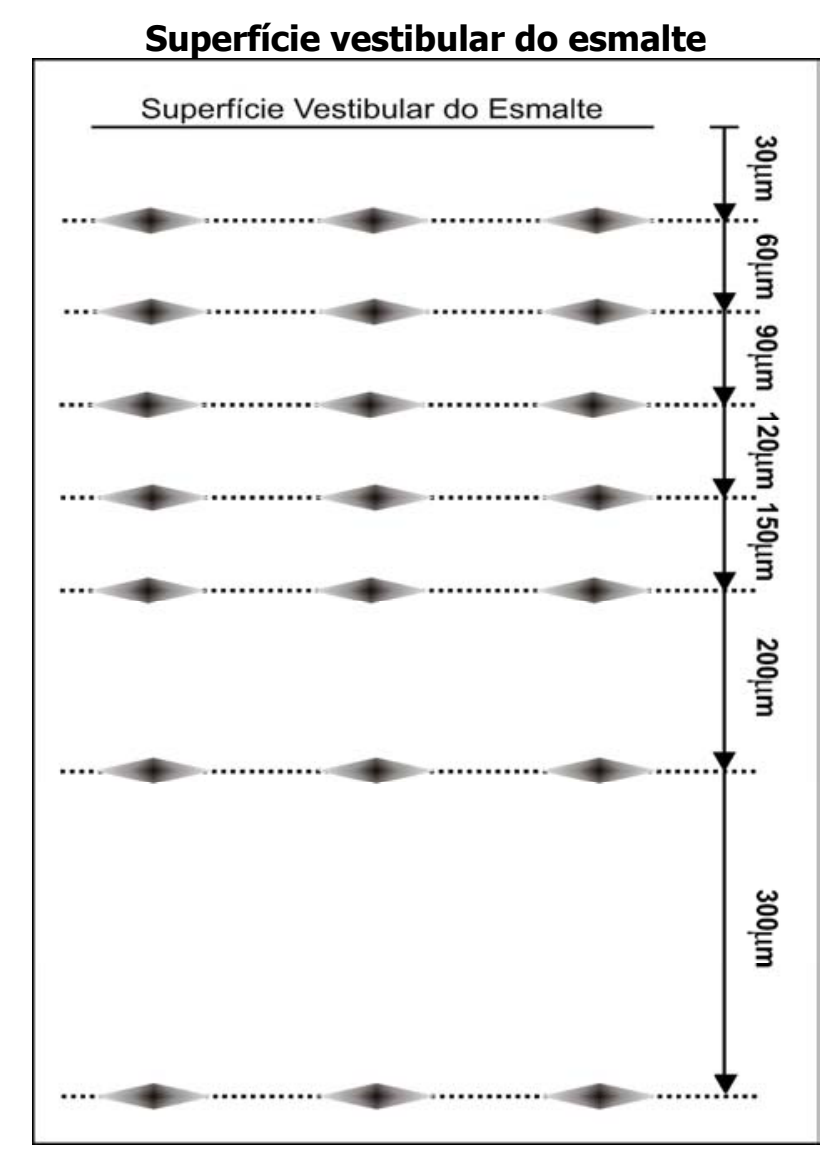

Figura 1 - Esquema de endentações para a avaliação da microdureza em profundidade, após secção longitudinal, no sentido vestíbulo-lingual, da coroa de dentes decíduos.

A metodologia deste experimento está representada esquematicamente na Figura 2. 


\subsection{MICROSCOPIA ELETRÔNICA DE VARREDURA}

Juntamente com os espécimes submetidos aos ciclos de imersão/agitação durante os 60 dias, foram acrescentadas 5 coroas de incisivos decíduos, em cada grupo, para a análise da superfície do esmalte em microscopia eletrônica de varredura (ZEICS EVO ${ }^{\circledR}$ 50 /2005, Cambridge England, 2005).

Nos períodos de 7, 15, 30, 45 e 60 dias, um espécime de cada grupo foi retirado e mantido em água deionizada, $\mathrm{a} \pm 4^{\circ} \mathrm{C}$.

Posteriormente, os espécimes foram preparados para a microscopia eletrônica de varredura com o seguinte protocolo: limpeza em cuba ultra-sônica por 5 minutos (Ultrasonic Cleaner T-1449-D. Odontobrás Ind. E Com., 14075-060, Ribeirão Preto, Brasil), desidratação em graus ascendentes de etanol: $25 \%, 50 \%, 75 \%, 95 \%$ e $100 \%$. Depois da secagem, os corpos-de-prova foram fixados em stubs com fita adesiva dupla-face de carbono (Electron Microscopy Sciences, Washington, PA 19034, USA) e a cobertura com ouro foi realizada em aparelho de metalização a vácuo (SDC 050, Bal-Tec AG, Foehrenwg 16, FL-9496 Balzers, Liechtenstein), com pressão média de $7,65 \times 10^{-5}$ Torr, corrente de $40 \mathrm{~mA}$, distância de trabalho de $13 \mathrm{~mm}$, tempo de cobertura de 80 segundos e espessura média de deposição de 20 a $30 \mathrm{~nm}$. Uma vez concluída a etapa de preparação, os espécimes foram levados ao microscópio eletrônico de varredura, do Laboratório de Microscopia Eletrônica de Varredura do Departamento de Química da Faculdade de Filosofia Ciências e Letras de Ribeirão Preto/USP. A superfície foi analisada, nos aumentos de 8000X e 20000X. Os achados microscópicos não foram analisados estatisticamente, tendo em vista que o intuito da análise morfológica será somente a comparação visual e qualitativa. 

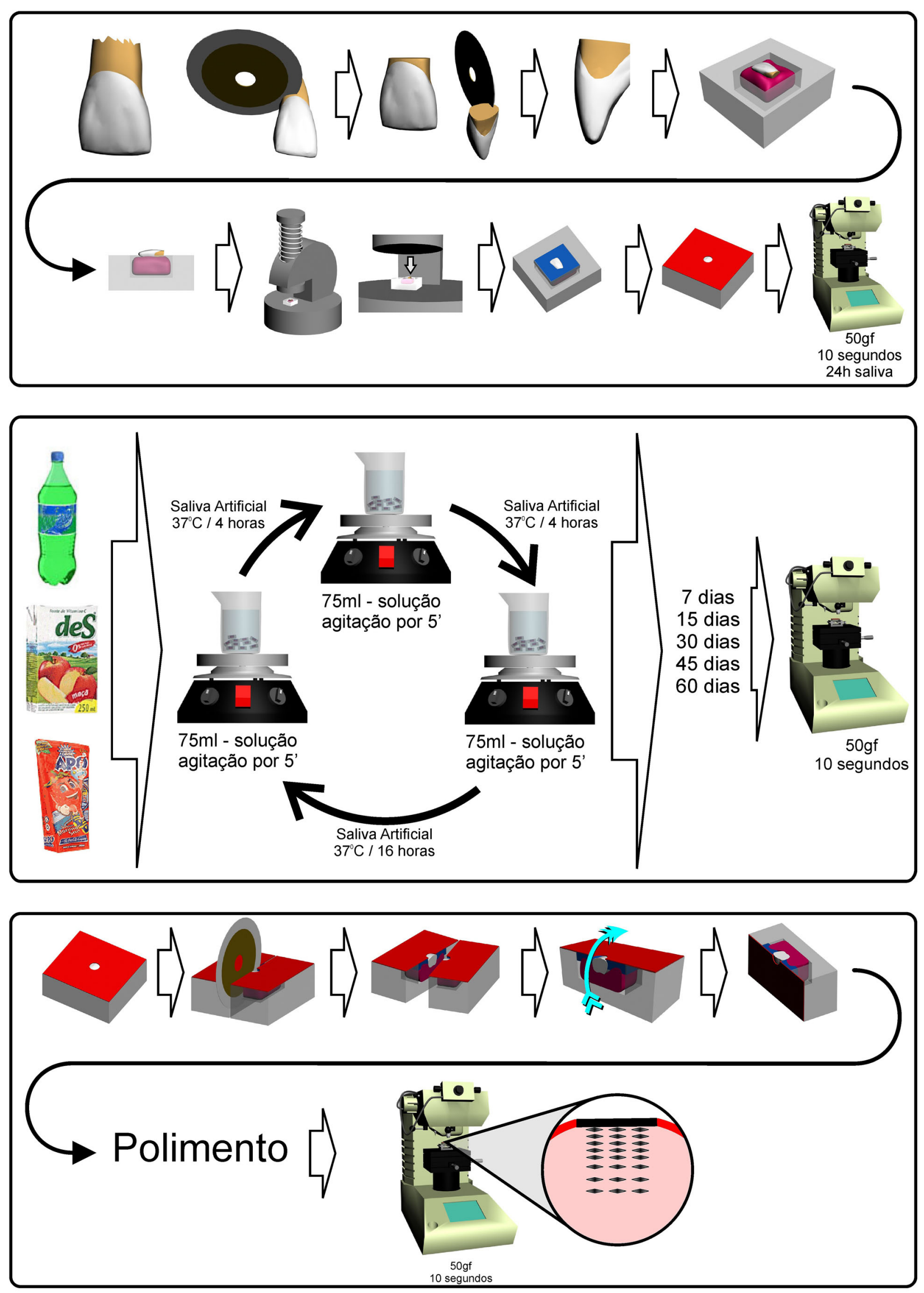

Figura 3 - Desenho esquemático da metodologia empregada. 


\subsection{ANÁLISE DOS DADOS}

Para a microdureza superficial, utilizou-se a Variação da Dureza Superficial (\%VDS) para as variáveis solução e tempo.

Para a microdureza em profundidade, realizou-se separadamente uma análise das médias de dureza nas diferentes profundidades, comparando-se as soluções utilizadas.

Os dados foram analisados, inicialmente, quanto à sua distribuição e homogeneidade através do Teste de Aderência à Curva Normal e Teste de Homogeneidade de Cochran.

Uma vez que os resultados dos testes responderam às pressuposições de normalidade e homogeneidade, empregou-se a Análise Interferencial através do teste paramétrico de Análise de Variância (ANOVA) a dois critérios. Assim sendo, foi realizada a ANOVA com os fatores de variações tempo/solução e solução/profundidade.

Pode-se observar que as soluções, o tempo, bem como suas interações apresentaram diferença estatisticamente significante (Quadro 1).

Quadro 1 - Análise de Variância: valores originais

\begin{tabular}{|c|c|c|c|c|c|}
\hline $\begin{array}{c}\text { Fonte de } \\
\text { Variação }\end{array}$ & $\begin{array}{c}\text { Soma dos } \\
\text { Quadrados }\end{array}$ & $\begin{array}{c}\text { Graus de } \\
\text { Liberdade }\end{array}$ & $\begin{array}{c}\text { Quadrados } \\
\text { Médios }\end{array}$ & F & Prob. (H0) \\
\hline Soluções & 155203 & 3 & 51734,32 & 326,98 & $0,0000 \% *$ \\
\hline Tempo & 42524,14 & 4 & 10631,04 & 67,19 & $0,0000 \% *$ \\
\hline SX T & 22851,24 & 12 & 1904,27 & 12,04 & $0,0000 \% *$ \\
\hline
\end{tabular}

* diferença estatisticamente significante

Para a diferenciação das médias dentro dos fatores, bem como nas suas interações, empregou-se o teste de Fisher, em nível de significância de 5\% $(a=0,05)$.

Para os valores de microdureza profunda. Pode-se observar que as soluções, a profundidade, bem como suas interações apresentaram diferença estatisticamente significante (Quadro 2): 
Quadro 2 - Análise de variância: valores originais

\begin{tabular}{|c|c|c|c|c|c|}
\hline $\begin{array}{c}\text { Fonte de } \\
\text { Variação }\end{array}$ & $\begin{array}{c}\text { Soma dos } \\
\text { Quadrados }\end{array}$ & $\begin{array}{c}\text { Graus de } \\
\text { Liberdade }\end{array}$ & $\begin{array}{c}\text { Quadrados } \\
\text { Médios }\end{array}$ & F & Prob. (H0) \\
\hline Soluções & 753150.1875 & 3 & 251050.0625 & 19.48 & $0.0005 \% *$ \\
\hline Profundidade & 535181.3750 & 7 & 76454.4844 & 75.00 & $0.0000 \% *$ \\
\hline S XP & 125843.4375 & 21 & 5992.5444 & 5.88 & $0.0000 \% *$ \\
\hline
\end{tabular}

* diferença estatisticamente significante

Para a diferenciação das médias dentro dos fatores, bem como nas suas interações, empregou-se o teste de Tukey, em nível de significância de 5\% $(a=0,05)$. 


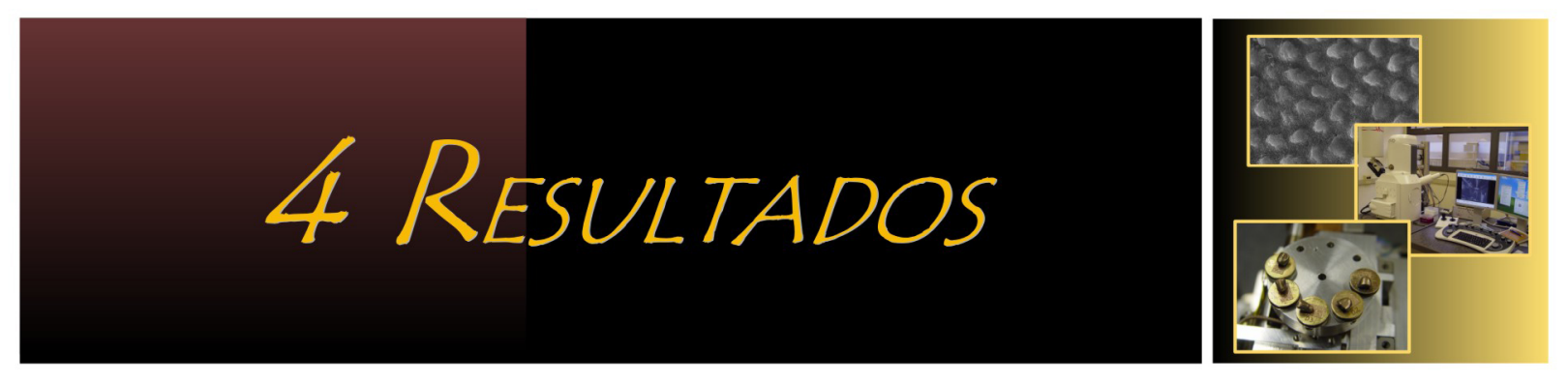




\section{Resultados}

\subsection{MICRODUREZA SUPERFICIAL(\%VDS)}

$\mathrm{Na}$ análise dos dados observou-se que para o fator solução, o Sprite ${ }^{\circledR}$ apresentou a maior variação de dureza superficial $(62,02 \%)$, sendo estatisticamente diferente do Kapo ${ }^{\circledR}$ morango $(49,05 \%)$ e do Ades $^{\circledR}$ Maçã $(40,56 \%)$, sendo todos diferentes estatisticamente entre si, e com a saliva (-11,31\%). Desta forma:

SALIVA ARTIFICIAL $<$ ADES MAÇÃ ${ }^{\circledR}<$ KAPO MORANGO ${ }^{\circledR}<$ SPRITE $^{\circledR}$

Para o fator tempo, houve uma perda progressiva e estatisticamente significante da microdureza ao longo dos períodos estudados, sendo todos os tempos diferentes entre si, ou seja:

$$
7(14,64)<15(29,93)<30(32,46)<45(46,89)<60(55,46)
$$

As médias obtidas para os grupos, de acordo com o tempo de exposição, bem como seus respectivos desvios-padrão, estão descritos no Quadro 3 e representados graficamente na Figura 3. 
Quadro 3 - Médias e desvios-padrão das soluções em função do tempo de exposição (\%VMS)

\begin{tabular}{|c|c|c|c|c|}
\hline TEMPO & SALIVA & ADES $^{\circledR}$ MAÇÃ & KAPO ${ }^{\circledR}$ MORANGO & SPRITE $^{\circledR}$ \\
\hline 7dias & $0,94( \pm 17,61) c$ & $5,67( \pm 20,07) \mathrm{c}$ & $16,85( \pm 12,97)$ cd & $35,12( \pm 12,16) \mathbf{f}$ \\
\hline 15 dias & $-18,94( \pm 15,71) \mathbf{b}$ & $31,08( \pm 27,9)$ ef & $39,42( \pm 24,84)$ ef & $52,15( \pm 22,33) \mathbf{f g}$ \\
\hline 30 dias & $-35,32( \pm 31,23) \mathbf{a}$ & $44,72( \pm 20,7) \mathbf{f g}$ & $55,07( \pm 13,54) \mathbf{g}$ & $65,39( \pm 14,14) \mathbf{g}$ \\
\hline 45 dias & $-11,54( \pm 48,69) \mathbf{b}$ & $59,36( \pm 24,46) \mathbf{g}$ & $63,88( \pm 87,07) \mathbf{g h}$ & $75,89( \pm 20,24) \mathbf{g i}$ \\
\hline 60 dias & $8,28( \pm 61,89)$ cd & $61,96( \pm 37,69) \mathbf{g}$ & $70,05( \pm 72,27) \mathbf{g h}$ & $81,55( \pm 10,7) \quad \mathbf{i}$ \\
\hline
\end{tabular}

* Letras iguais indicam similaridade estatística

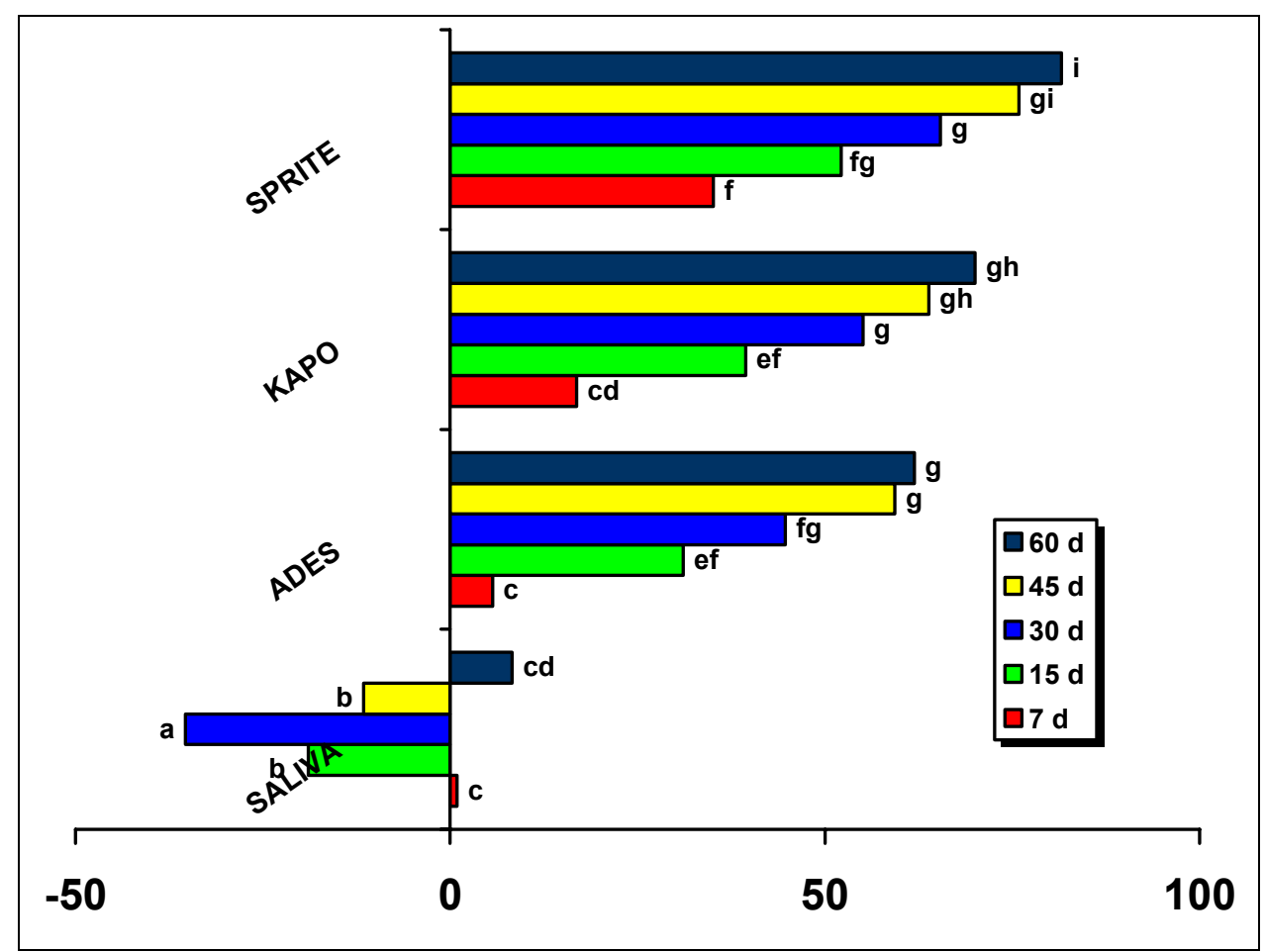

Figura 3 - Representação gráfica dos valores (\%VMS) obtidos para os grupos, de acordo com o tempo de exposição.

$\mathrm{Na}$ interação tempo $X$ solução, observou-se que o grupo da saliva apresentou um ganho de microdureza superficial gradativo significante até 30 dias, ocorrendo então sua diminuição aproximando-se dos valores iniciais. Para o suco Ades ${ }^{\circledR}$ maçã houve perda significante $(p<0,05)$ na microdureza, em todos os períodos, sendo mais evidente após 60 
dias de imersão na solução. O suco Kapo ${ }^{\circledR}$ morango apresentou uma alteração gradativa e estatisticamente significante na microdureza em todos os períodos de tempo avaliados, porém afetando o esmalte de forma mais intensa que o suco Ades ${ }^{\circledR}$ maçã. O refrigerante Sprite ${ }^{\circledR}$ apresentou uma diminuição gradual e significante em todos os períodos avaliados atingindo $81,55 \%$ de variação na microdureza superficial aos 60 dias.

\subsection{MicroduREza PROFUnda}

Em relação à microdureza profunda, pôde-se observar que, entre as soluções, houve diferença estatística, entre os grupos experimentais Sprite ${ }^{\circledR}(117,98 \mathrm{KHN})$ e o Ades $^{\circledR}$ Maçã $(188,18 \mathrm{KHN})$. O Kapo ${ }^{\circledR}$ Morango (157.27 KHN) apresentou-se estatisticamente semelhante ao $\operatorname{Ades}^{\circledR}$ Maçã e ao Sprite $^{\circledR}$. O grupo controle $(250,66 \mathrm{KHN})$, apresentou microdureza superior e estatisticamente diferente das bebidas experimentais. Resumindo tem-se:

\section{SALIVA ARTIFICIAL > ADES ${ }^{\circledR}$ MAÇÃ $\approx$ KAPO ${ }^{\circledR}$ MORANGO SPRITE ${ }^{\circledR}$ ADES $^{\circledR}$ MAÇÃ > SPRITE ${ }^{\circledR}$}

Em relação às profundidades, observou-se que a dureza superficial $(107,14$ KHN) foi estatisticamente diferente das demais. Na profundidade de $30 \mu \mathrm{m}$ da superfície (135,64 KHN) ocorreu semelhança estatística com a profundidade de $60 \mu \mathrm{m}(156,02 \mathrm{KHN})$, que por sua vez foi semelhante à profundidade de $90 \mu \mathrm{m}(172,74 \mathrm{KHN})$, sendo que esta foi diferente estatísticamente de $30 \mu \mathrm{m}$ e semelhante à profundidade de $120 \mu \mathrm{m}(193,08 \mathrm{KHN})$. A microdureza na profundidade de $120 \mu \mathrm{m}$ foi semelhante a $150 \mu \mathrm{m}(193,08 \mathrm{KHN})$ e diferentes de 30, 60 e $90 \mu \mathrm{m}$. A profundidade de $200 \mu \mathrm{m}(232,38 \mathrm{KHN})$ foi semelhante somente a $300 \mu \mathrm{m}$ (Quadro 4). 
Quadro 4 - Fator de variação: profundidade

\begin{tabular}{|l|l|l|l|l|l|l|l|}
\hline Superfície & $\mathbf{3 0} \boldsymbol{\mu m}$ & $\mathbf{6 0} \boldsymbol{\mu m}$ & $\mathbf{9 0} \boldsymbol{\mu m}$ & $\mathbf{1 2 0} \boldsymbol{\mu m}$ & $\mathbf{1 5 0} \boldsymbol{\mu m}$ & $\mathbf{2 0 0} \boldsymbol{\mu m}$ & $\mathbf{3 0 0} \boldsymbol{\mu m}$ \\
\hline $107,14 \mathbf{g}$ & $135,64 \mathbf{f}$ & 156,02 ef & $172,94 \mathbf{~ d e}$ & $193,08 \mathbf{c d}$ & $210,88 \mathbf{b c}$ & $232,38 \mathbf{a}$ & $220,30 \mathbf{a b}$ \\
\hline
\end{tabular}

* Letras iguais indicam similaridade estatística

As médias obtidas para os grupos, de acordo com a profundidade avaliada, bem como seus respectivos desvios-padrão estão descritos no Quadro 5, e representados graficamente na Figura 4.

Quadro 5 - Médias (KHN) e desvios-padrão das soluções em função das profundidades avaliadas.

\begin{tabular}{|c|c|c|c|c|}
\hline & SALIVA & SPRITE $^{\circledR}$ & ADES $^{\circledR}$ MAÇÃ & $\begin{array}{l}\text { KAPO }^{\circledR} \\
\text { MORANGO }\end{array}$ \\
\hline Superfície & $220,40( \pm 61,88) \mathbf{a}$ & $44,11( \pm 10,70) \mathrm{C}$ & $91,79( \pm 35,31)$ b & $\begin{array}{l}72,27 \\
( \pm 24,61) \text { bc }\end{array}$ \\
\hline $30 \mu \mathrm{m}$ & $220,90( \pm 39,42) \mathbf{a}$ & $71,77( \pm 28,69) \mathbf{c}$ & $141,83( \pm 50,67) \mathbf{b}$ & $\begin{array}{l}108,07 \\
( \pm 36,32) \text { bc }\end{array}$ \\
\hline $60 \mu \mathrm{m}$ & $233,70( \pm 27,46) \mathbf{a}$ & $89,39( \pm 35,50) \mathbf{c}$ & $173,45( \pm 60,92) \mathbf{b}$ & $\begin{array}{l}127,54 \\
( \pm 36,17) \text { bc }\end{array}$ \\
\hline $90 \mu \mathrm{m}$ & $253,50( \pm 34,24) \mathbf{a}$ & $101,28( \pm 42,09) \mathrm{C}$ & $190,9 \quad( \pm 68,87) \mathbf{b}$ & $\begin{array}{l}145,30 \\
( \pm 41,52) \text { bc }\end{array}$ \\
\hline $120 \mu \mathrm{m}$ & $267,90( \pm 42,80) \mathbf{a}$ & $121,94( \pm 58,60) \mathbf{c}$ & $210,10( \pm 67,61) \mathbf{b}$ & $\begin{array}{l}172,40 \\
( \pm 45,62) \text { bc }\end{array}$ \\
\hline $150 \mu \mathrm{m}$ & $278,00( \pm 33,47) \mathbf{a}$ & $142,94( \pm 68,00) \mathbf{c}$ & $227,70( \pm 68,73) \mathbf{b}$ & $\begin{array}{l}194,90 \\
( \pm 40,17) \text { bc }\end{array}$ \\
\hline $200 \mu \mathrm{m}$ & $310,90( \pm 37,52) \mathbf{a}$ & $157,82( \pm 71,26) \mathbf{C}$ & $244,00( \pm 50,82) \mathbf{b}$ & $\begin{array}{l}216,80 \\
( \pm 47,66) \mathbf{b}\end{array}$ \\
\hline $300 \mu \mathrm{m}$ & $220,00( \pm 58,42) \mathbf{a}$ & $214,60( \pm 68,73) \mathbf{a}$ & $225,73( \pm 74,43) \mathbf{a}$ & $\begin{array}{l}220,90 \\
( \pm 48,42) \mathbf{a}\end{array}$ \\
\hline
\end{tabular}

* Letras iguais indicam similaridade estatística na comparação na linha (na mesma profundidade para as diferentes soluções) 


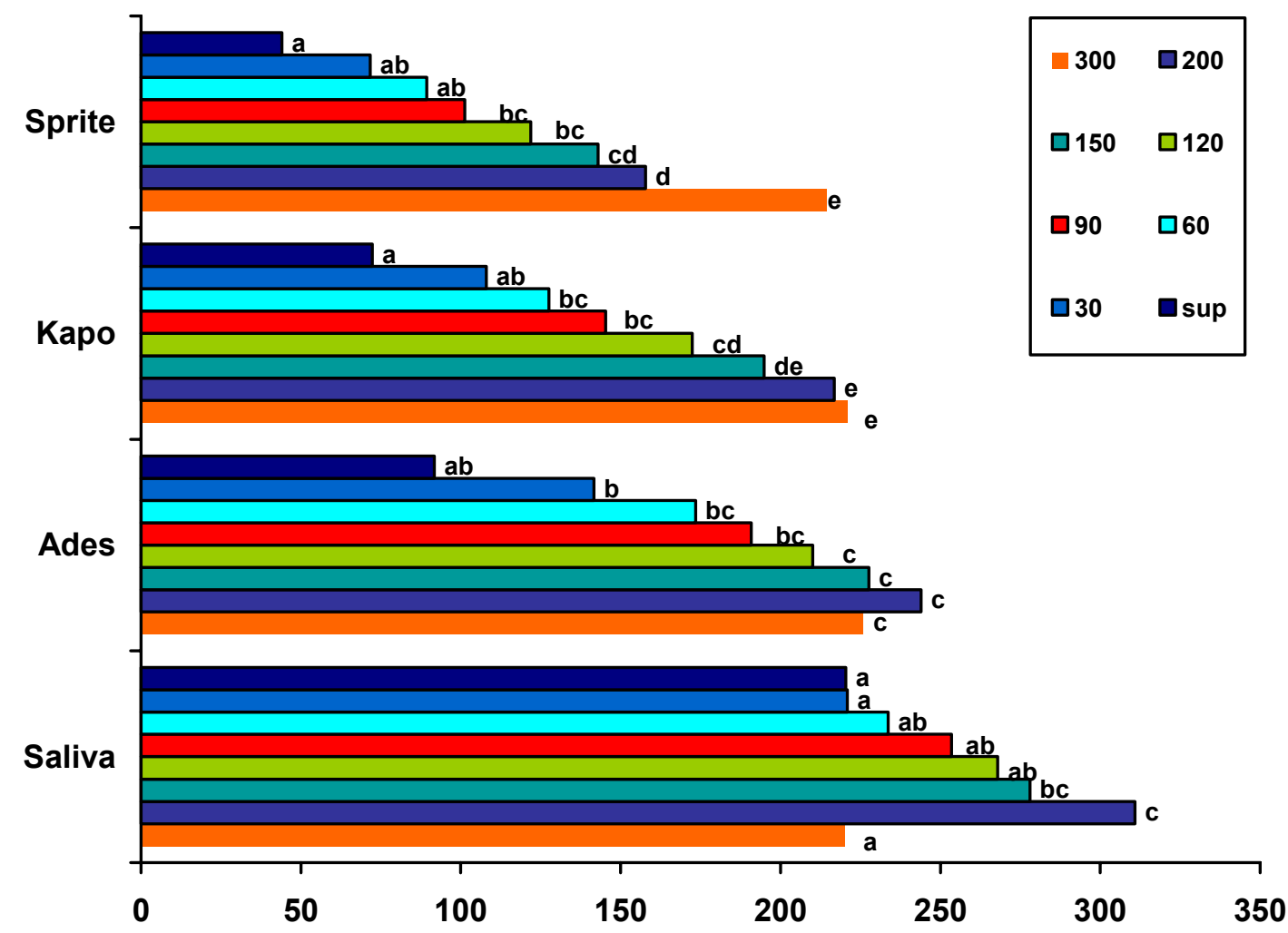

Figura 4 - Representação gráfica dos valores obtidos para os grupos, de acordo com a soluções avaliadas. As letras indicam similaridade estatística nas soluções para as diferentes profundidades.

$\mathrm{Na}$ interação dos fatores solução $X$ profundidade, observou-se que apenas em $300 \mu m$ é que ocorreu semelhança entre as quatro soluções estudadas. Para o grupo controle, observou-se que a superfície apresentou microdureza semelhante à subsuperfície, aumentando seus valores gradativamente até $200 \mu \mathrm{m}$, havendo uma diminuição estatisticamente significante aos $300 \mu \mathrm{m}$ de profundidade. Em relação ao suco de Maçã $\operatorname{Ades}^{\circledR}$, observou-se menor microdureza na superfície, sendo esta estatisticamente inferior às outras profundidades, ocorrendo um aumento gradual significativo até $200 \mu \mathrm{m}$ diminuindo de modo não significativo aos $300 \mu \mathrm{m}$ de profundidade. O suco de morango Kapo ${ }^{\circledR}$ apresentou comportamento semelhante ao Ades Maçã até $200 \mu \mathrm{m}$, aumentando de modo não significativo na subsuperfície de $300 \mu \mathrm{m}$. Quanto ao refrigerante Sprite ${ }^{\circledR}$ observou-se um aumento gradual e estatisticamente significante até $300 \mu \mathrm{m}$ de profundidade. Entretanto, 
este grupo promoveu menores medidas de microdureza nas profundidades de 30 a $120 \mu \mathrm{m}$, demonstrando maior poder de penetração desta bebida no esmalte.

\subsection{MiCROSCOPIA ELETRÔNICA DE VARREDURA}

Pôde-se observar em microscopia eletrônica de varredura que o grupo do Sprite ${ }^{\circledR}$, apresentou crescente alteração da superfície do esmalte, com o aumento do tempo de exposição. Após 7 dias de imersão observou-se uma intensa desmineralização de toda a superfície, sendo mais pronunciada na porção interprismática, no entanto, houve remoção parcial do centro dos prismas de esmalte, havendo uma protrusão dos mesmos (Figura 5A). Aos 15 dias de exposição, a superfície do esmalte tornou-se mais porosa, havendo uma redução no tamanho dos centros dos prismas (Figura 5B). Aos 30 dias de exposição, houve aparente perda de minerais, aumentando ainda mais a porosidade do esmalte superficial (Figura 5C). Aos 45 dias de imersão houve eliminação completa do centro dos prismas formando concavidades (Figura 5D). Após 60 dias de imersão, pôde-se observar uma nítida perda generalizada de estrutura do esmalte, desgastando tanto o centro como a periferia dos prismas de esmalte (Figuras 5E e 5F), diferenciando-se das superfícies imersas em saliva artificial, em que não se observou alterações microestruturais superficiais (Figuras 8A e 8B, 8C e 8D).

A solução Kapo ${ }^{\circledR}$ morango, aos 7 dias de exposição (Figura 6A), removeu todo o esmalte aprismático, expondo os prismas de esmalte, atacando mais o centro do que a periferia dos prismas. Ao decorrer dos períodos analisados, houve uma desmineralização gradual e homogênea, sendo que após 30 dias (Figura 6C), a superfície do esmalte encontrava-se planificada, sendo mais evidenciada aos 45 dias de exposição (Figura 6D), onde os centros dos prismas ficaram mais expostos, havendo erosão irregular. Aos 60 dias de imersão, houve um colapso dos cristais de apatita causado pela intensa desmineralização, formando cavidades bem evidenciadas (Figura 6E e F). 
Em relação ao Ades $^{\circledR}$ Maçã, aos 7 dias de exposição (Figura 7A), a desmineralização superficial não foi capaz de remover a camada aprismática de esmalte, deixando esta intacta até os 15 dias de exposição (Figura 7B). Após 30 dias de exposição (Figura 7C), pôde-se observar irregularidades na superfície do esmalte, que se apresentava irregular com aparecimento de crateras superficiais. A imersão após 45 dias (Figura 7D) promoveu uma desmineralização superficial generalizada, sem atacar áreas específicas, demonstrando uma superfície desgastada e irregular sendo mais evidente após 60 dias de imersão (Figuras E e F). 
Figura 5 - ESMALTE IMERSO EM SPRITE

A - Após 7 dias de imersão - Observa-se intensa desmineralização mais pronunciada na porção interprismática e remoção parcial do centro dos prismas.

B - 15 dias de imersão - Esmalte tornou-se mais poroso com maior desgaste dos centros dos prismas.

C - 30 dias de imersão - Nota-se desmineralização generalizada.

D - 45 dias de imersão - Eliminação completa dos centros dos prismas formando concavidades.

E e F - 60 dias de imersão - Intensa desmineralização com protrusão dos centros dos prismas. Detalhe dos centros dos prismas e porosidade do esmalte interprismático. 

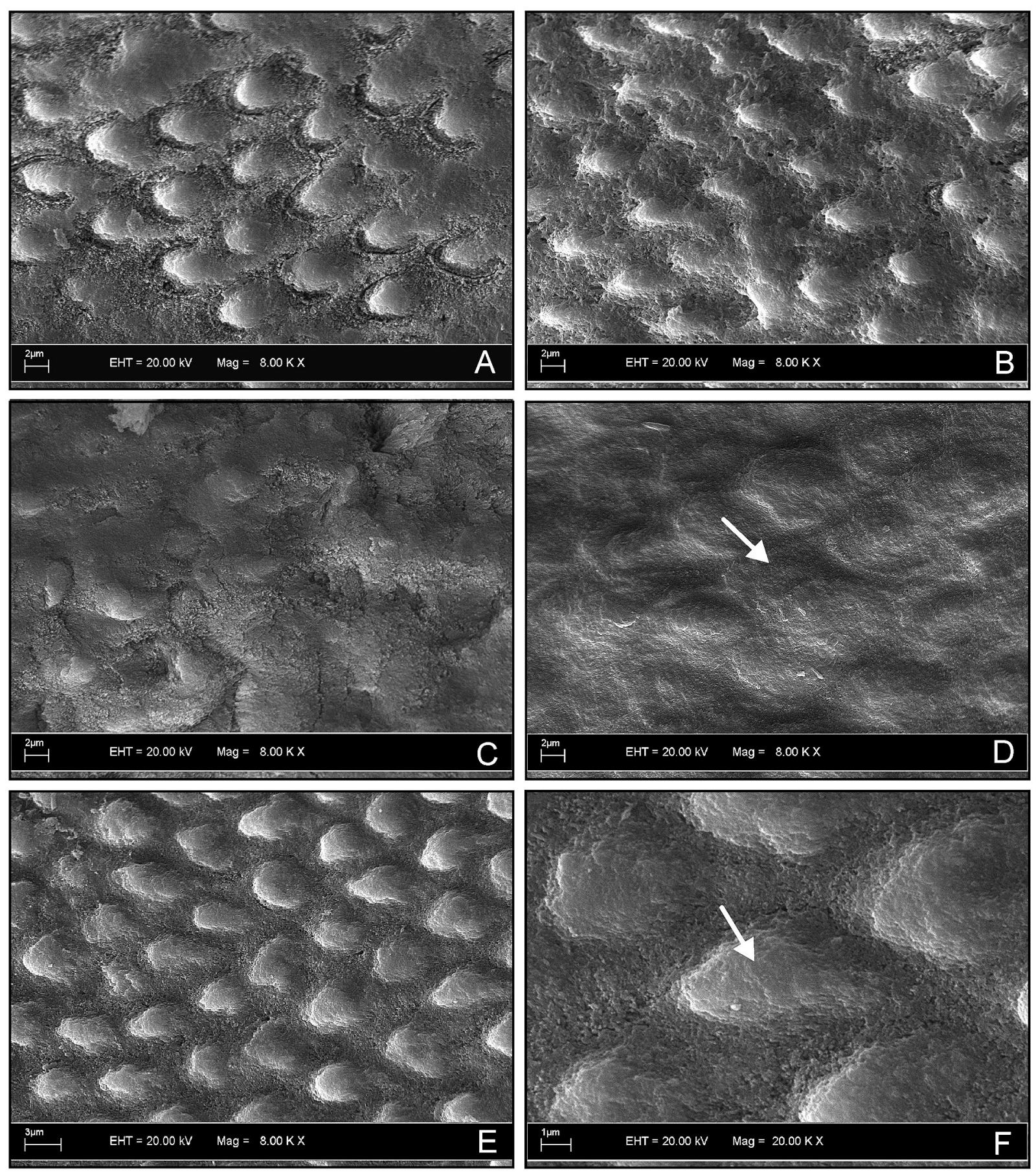
Figura 6 - ESMALTE IMERSO EM KAPO ${ }^{\circledR}$ MORANGO

A - Após 7 dias de imersão - Remoção de todo esmalte aprismático.

B - Após 15 dias de imersão - Exposição dos prismas de esmalte.

C - 30 Dias - Desmineralização gradual e homogênea do esmalte.

D - 45 Dias - Centro dos prismas expostos havendo erosão irregular.

E e F - 60 Dias de imersão - Intensa desmineralização formando cavidades bem evidenciadas. Detalhe do centro dos prismas de esmalte (concavidades). 

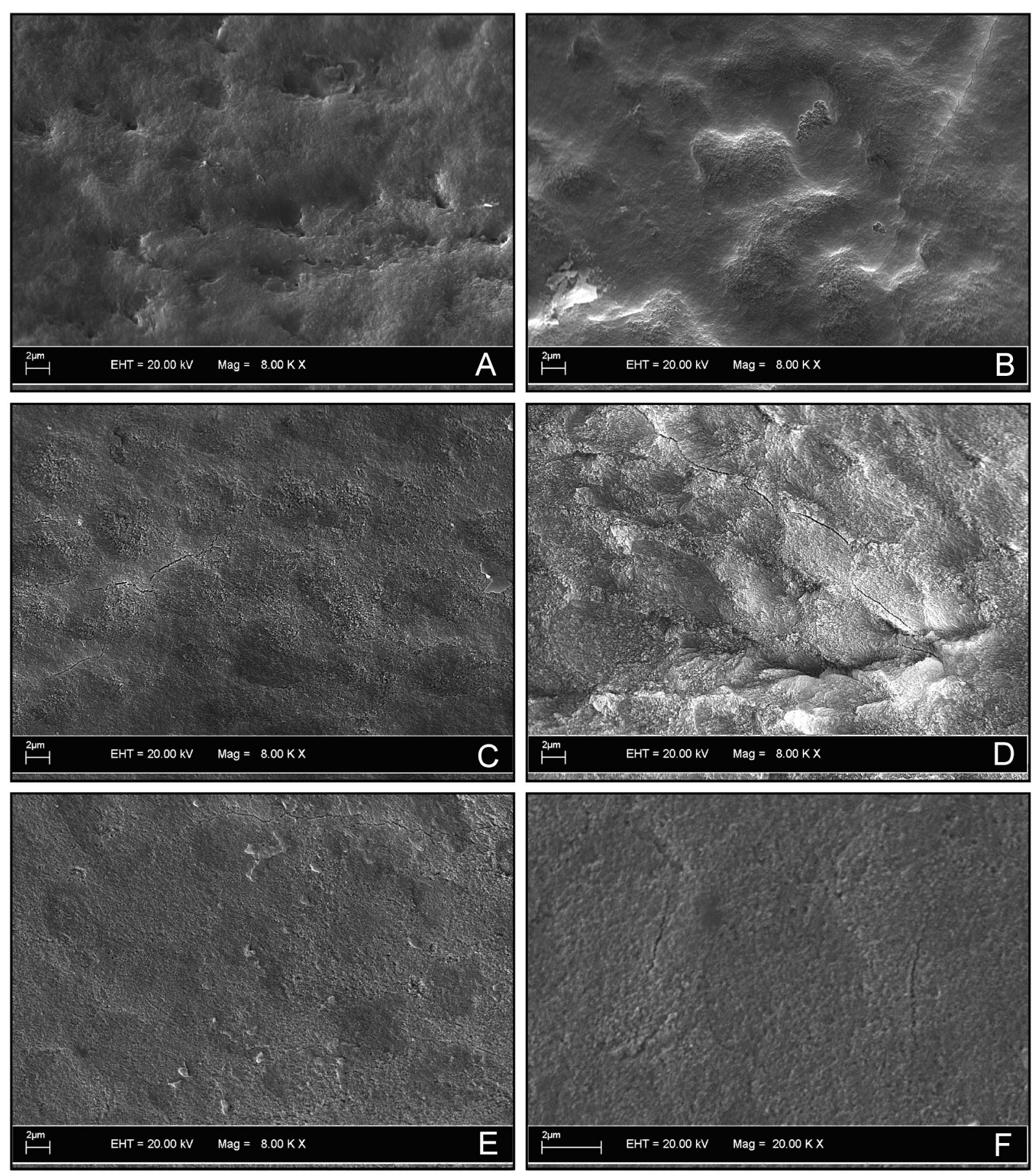
Figura 7 - ADES MAÇÃ

A e B - 7 e 15 dias de imersão - Desmineralização superficial com manutenção da camada aprismática.

C - 30 dias de imersão - Irregularidades na superfície do esmalte com o aparecimento de crateras.

D - 45 dias - Desmineralização superficial generalizada.

E e F - 60 dias - superfície desgastada irregular. 

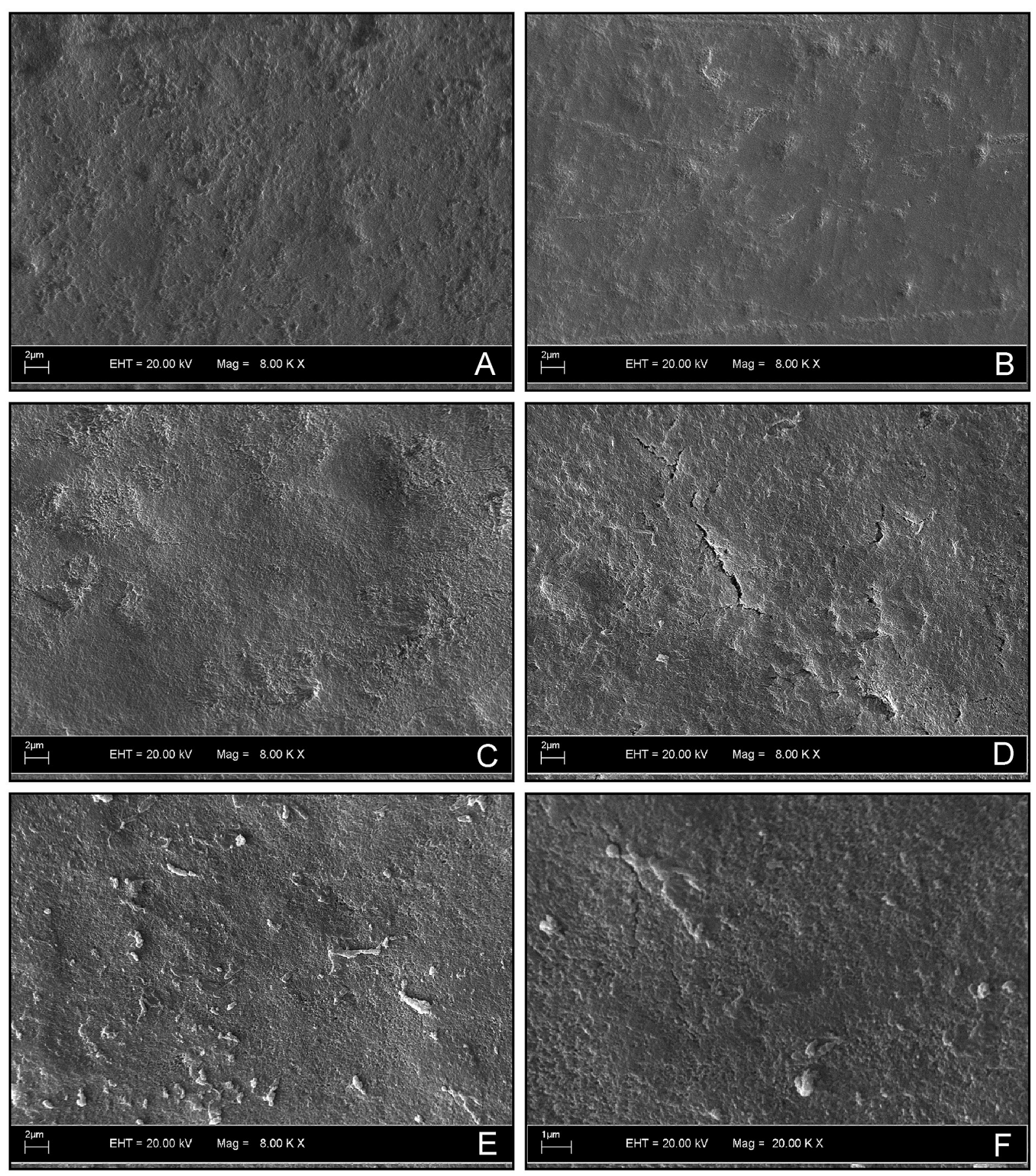
Figura 8 - SALIVA ARTIFICIAL
A e B - 7 dias de imersão em saliva
C e D - 60 dias de imersão sem alterações microestruturais superficiais. 

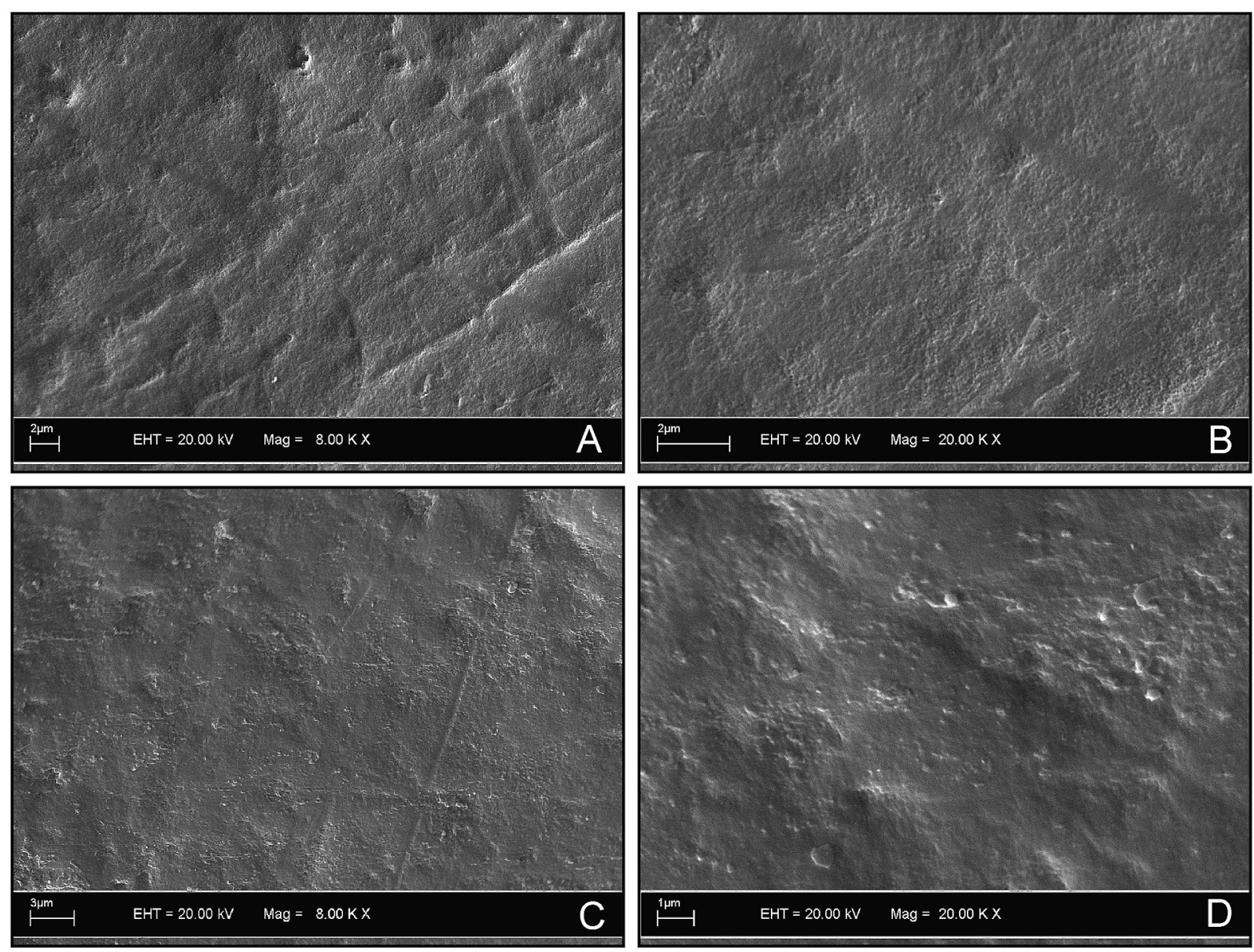


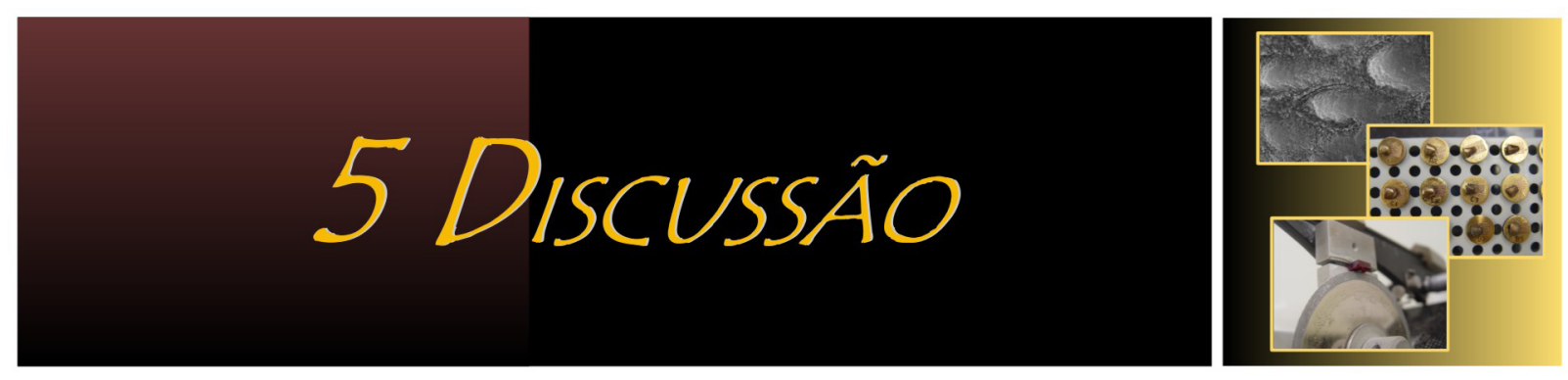




\section{Discussão}

Os resultados deste estudo demonstraram que o Sprite ${ }^{\circledR}$, o Ades ${ }^{\circledR}$ Maçã e o Kapo ${ }^{\circledR}$ Morango, frequentemente consumidos durante a alimentação de crianças, possuem potencial erosivo sobre o esmalte de dentes decíduos. No entanto, as bebidas ácidas apresentam diferentes potenciais erosivos, de acordo com suas características de $\mathrm{pH}$, capacidade tampão, concentração de cálcio, flúor e fosfato, tipo de ácido (Lussi et al., 1995; Larsen e Nyvad, 1999; Attin et al., 2003) e temperatura (Barbour et al., 2006).

Neste estudo foram analisados o pH das soluções e o tipo de ácido de cada bebida. De uma forma complementar, muitos trabalhos avaliam também a capacidade tampão. Porém, sendo esta, o poder de uma solução manter estável seu pH quando uma pequena quantidade de ácido ou base é adicionada, a quantidade total de ácido ou $\mathrm{pH}$ reflete diretamente o potencial erosivo de uma bebida sobre os dentes (Seow e Thong, 2005). Ou seja, quanto mais baixo o pH, maior a quantidade de hidróxido de sódio $(\mathrm{NaOH})$ necessária para neutralizar uma solução, menor será sua capacidade tampão (Larsen e Nyvad, 1999).

Além disso, a análise do $\mathrm{pH}$ é o método mais prático para avaliar o potencial erosivo das bebidas, uma vez que a dissolução do esmalte ocorre em pH crítico $(5,5)$ e muitas bebidas disponíveis comercialmente possuem potencial erosivo ao esmalte em decorrência do baixo $\mathrm{pH}$. As bebidas carbonatadas variam o pH de 2,3 a 3,4 e sucos de fruta de 2,1 a 3,6 aproximadamente (Larsen e Richards 2002).

No presente trabalho, a bebida a base de limão (Sprite ${ }^{\circledR}$ ), apresentou pH 2,9, o suco de morango $\left(\mathrm{Kapo}^{\circledR}\right)$, $\mathrm{pH} 3,7$, que de acordo com o fabricante apresenta $150 \mathrm{mg}$ de cálcio em sua composição, e pH 4,06 para o suco de maçã a base de soja (Ades ${ }^{\circledR}$ ).

Com relação à análise da microdureza Knoop, a maior variação de microdureza superficial (\%VMS) foi observada para o refrigerante à base de limão $(62,02 \%)$, 
sendo estatisticamente diferente do suco de morango $(49,05 \%)$ e do e do suco de maçã à base de soja $(40,56 \%)$ e diferentes estatisticamente da saliva $(-11,31 \%)$. Este padrão linear de erosão em função do tempo, também foi notado com esmalte bovino e humano em estudos in vitro e in situ, de acordo com Grando et al., 1996 e Larsen e Nyvad, 1999; Eisenburger et al., 2000; Pontefract et al., 2001, que afirmaram que quanto maior o tempo de exposição, maior a erosão.

Lussi et al, 1993 demonstraram, em dentes permanentes, que o refrigerante à base de limão Sprite ${ }^{\circledR}$ Light $(\mathrm{pH} 2,88)$, apresentou menores valores de microdureza superficial em relação ao suco de pomelo, suco de maçã e do molho para salada.

Em estudo posterior, Lussi et al.,(2000), ao comparar o potencial erosivo de diferentes bebidas na dentição decídua e permanente, analisando pH, capacidade tampão, quantidade de cálcio, fosfato e fluoretos, verificaram que o refrigerante à base de limão Sprite ${ }^{\circledR}$ degazeificado ( $\mathrm{pH} 2,64$ ), em 3 minutos de imersão, apresentou os menores valores de microdureza tanto em dentes decíduos quanto em permanentes.

Neste estudo, o suco de morango Kapo ${ }^{\circledR}$ apresentou o segundo maior potencial erosivo, apesar da suplementação de cálcio que esta bebida contém. Segundo Attin et al., 2003, o aumento de fluoretos e do cálcio reduz os efeitos negativos da desmineralização do esmalte dentário. Porém, a dissolução do esmalte não é prevenida simplesmente pela adição destes compostos. Segundo Larsen, 2001, na maioria das bebidas ácidas adicionadas de cálcio que contém ácido cítrico em sua composição, ocorre uma ligação química cálcio-citrato tornando limitado seu efeito preventivo sobre a erosão. Segundo Hughes et al., 2000, a adição de 0,24 g de cálcio em $100 \mathrm{ml}$ de ácido cítrico em um pH de 3,8 reduz a erosão do esmalte dentário em $50 \%$. Porém, com a redução do pH, este efeito não foi observado.

Segundo estudo realizado por Larsen e Nyvad, 1999, as concentrações de íons cálcio e fosfato nas bebidas ácidas geralmente são baixas e não efetivas na prevenção da 
erosão, além disso, a adição de cálcio e o aumento do pH geram um sabor de menor aceitação (Grenby, 1996). Associado a isso, o aumento do pH resulta em formulações mais susceptíveis à proliferação bacteriana (Barbour et al.2003). Segundo Attin et al., 2003, para o ajuste ideal de uma bebida ácida, a administração de cálcio, fosfatos e fluoretos à solução deve ser individualmente analisada para cada bebida.

Quanto ao tipo de ácido, as bebidas utilizadas no presente estudo continham ácido cítrico, de acordo com seus fabricantes. Muitos autores mostraram que o ácido cítrico, comumente utilizado nas bebidas possui um elevado potencial erosivo (Hughes et al., 2000; Larsen, 2001; Attin et al., 2003; Barbour et al., 2003).

Estudos in vitro são fundamentais para predizerem o potencial erosivo e características químicas das bebidas (Lussi et al.,1993; Lussi et al., 1995; Larsen e Nyvad, 1999; Hughes et al., 2000, West et al. 2001; Barbour et al., 2003) e, a maioria destes, consideram os aspectos químicos da erosão. Porém, os aspectos físicos como padrão individual de deglutição, fluxo salivar, formação de película adquirida, hábitos dietéticos individuais têm papel primordial na prevenção dessas lesões (Shellis et al., 2005). Estudos in situ mostraram variações significantes inter-sujeitos na erosão do esmalte mesmo em condições controladas de estudo, suportando a idéia de susceptibilidade (Hughes et al., 2000; Hooper et al., 2007).

Na tentativa de minimizar as diferenças entre este e os estudos in vivo ou in situ, foi utilizada neste estudo a saliva artificial para a manutenção dos espécimes nos intervalos imersão-agitação, na tentativa de compensar as limitações de um estudo in vitro. Em algumas pesquisas (Rytommaa et al., 1998; Maupomé et al., 1999; Amaechi et al., 1999; Einsenburger et al., 2001; Van Eygen et al., 2005) observou-se que a manutenção dos espécimes em saliva, nos intervalos das imersões nas soluções experimentais promoveu menor erosão do esmalte. A saliva artificial foi utilizada baseada no estudo de Amaechi e Higham (2001), no qual demonstraram que esta obteve o mesmo efeito da saliva humana 
fresca. Além disso, a longa duração do presente estudo (60 dias), dificultaria a coleta de saliva humana fresca.

Seow e Thong, 2005 compararam saliva humana e água mineral Evian ${ }^{\circledR}$ para prevenir a perda de minerais da superfície do esmalte, quando expostos ao desafio erosivo e, observaram que, a saliva pode neutralizar os ácidos através do fosfato e proteínas e pela alta concentração mineral.

A saliva artificial utilizada neste experimento continha cálcio, fosfato e flúor, que possui um efeito remineralizador em esmalte humano desmineralizado artificialmente como relatado em estudos prévios (Lussi et al., 2000; Van Eygen et al., 2005). Fato que foi observado neste estudo em esmalte de dentes decíduos hígidos obtidos para o grupo controle, no qual se pôde notar um ganho de microdureza superficial gradativo significante até 30 dias, ocorrendo então sua diminuição aproximando-se dos valores iniciais.

Assim, a saliva é responsável pela diluição e limpeza das substâncias erosivas, pela neutralização e tamponamento dos ácidos, manutenção de um estado super-saturado próximo à superfície do dente além de fornecer cálcio, fosfato e fluoretos necessários na remineralização e formação da película adquirida (Zero e Lussi, 2005).

A principal função da película adquirida é limitar a difusão do ácido e influenciar no transporte de íons, agindo como uma membrana seletiva na superfície do esmalte (Maupomé et al., 1999; Lendenmann et al., 2000, Hara et al., 2006). Qualquer procedimento que remova ou reduza a espessura dessa película pode comprometer suas propriedades protetoras e acelerar o processo erosivo (Zero e Lussi, 2005). Neste estudo, todos os espécimes permaneceram em saliva artificial durante 4 horas, nos intervalos entre as três imersões diárias. O tempo necessário para a formação da película adquirida a fim de promover ótima proteção, ainda é controverso, com estudos relatando um mínimo de 3 minutos (Hanning et al., 2004), 2 horas (Lendemann et al., 2000); 7 dias (Meurman e Frank, 1991). Isso pode ser explicado devido a diferenças metodológicas e, principalmente, pelas 
condições para a formação da película (in situ X in vitro) e métodos analíticos (Zero e Lussi, 2005).

Na avaliação da microdureza de qualquer substrato é necessário que as superfícies estejam planas e polidas para a realização da correta leitura (Torres, 2005). Segundo Lussi et al., 1995, para medir as endentações de uma forma simétrica, é necessário o polimento. Entretanto, em dentes decíduos, o polimento remove a camada aprismática, que alguns autores consideram mais resistente ao ataque ácido, sendo que sua remoção torna o dente mais susceptível à desmineralização (Meurman e Frank, 1991; Lussi et al., 1993).

Considerando a importância da camada aprismática, presente nos dentes decíduos (Meurman e Frank, 1991), optou-se pela não remoção desta, tornando este estudo mais fiel às condições que ocorrem na cavidade bucal. Além disso, a falta de padronização do polimento pode deixar algumas superfícies com menor espessura de esmalte, afetando de forma diferenciada os grupos experimentais.

Para se obter a planificação necessária, para as leituras no microdurômetro, neste estudo, foi utilizado o paralelômetro previamente à fixação da coroa, a fim de assegurar que a superfície vestibular estivesse paralela à base e perpendicular à ponta do microdurômetro.

Neste experimento, foi utilizado o tempo de 5 minutos de imersão para simular o período médio de ingestão das bebidas. Meurman et al., 1990, observaram em um estudo in vitro que o tempo de 5 minutos de imersão no esmalte de uma bebida à base de cola, proporcionou desmineralização significativa enquanto o tempo de um minuto de imersão não proporcionou. Porém, em relação a este período, os estudos têm sido controversos. Larsen e Nyvad, 1999, induziram erosão utilizando 1,5 litros de bebidas ácidas sob contínua agitação durante uma semana. No entanto, relataram que esta exposição foi de grande intensidade e distante da realidade. Alegaram que o potencial erosivo é mais 
evidente por um período prolongado de exposição e mesmo as bebidas menos erosivas evidenciam erosão nessas condições.

Neste sentido, para que um período de 5 minutos de imersão pudesse ser utilizado, o tempo total do experimento neste estudo foi de 60 dias, que excede os utilizados nas pesquisas descritas na literatura. Como a erosão é considerada um processo, as alterações no substrato ocorrem em função do tempo a que são expostos às bebidas. Assim, tanto a freqüência de ingestão, quanto o tempo de consumo é que vão determinar a gravidade desta patologia (Torres, 2005).

As imersões foram realizadas sob agitação para simular a forma como os dentes são banhados no momento da ingestão da bebida. Segundo Van Eygen et al., 2005, o estado da bebida (estático ou sob agitação) foram comparados, e uma vez que os líquidos são ingeridos sob um processo dinâmico e fisiológico no qual o líquido entra em contato com os dentes, justifica-se a agitação. Além disso, a dinâmica produzida pela agitação permite que haja renovação do líquido sobre a estrutura do esmalte. Em contrapartida, Maupomé et al., 1998, mostrou que a agitação aumenta a superfície de contato com os espécimes podendo aumentar o grau de erosão. Em um estudo subseqüênte (Maupomé et al., 1999) verificaram que nas mesmas condições do experimento anterior, mas mantendo os espécimes em saliva nos intervalos das imersões ocorria uma diminuição no grau de erosão do esmalte em condições de agitação.

A utilização de três ciclos de imersão/agitação foi estabelecida em função de uma média de freqüência de ingestão dessas bebidas, que ocorre durante as principais refeições por crianças na fase de dentição decídua (Torres, 2005). Assim, não há padronização do número de ciclos imersão/ agitação. Maupomé et al., 1998 utilizaram três ciclos de imersão, enquanto outros autores realizaram uma única imersão (Lussi et al., 1993; Lussi et al., 1995; Hughes et al., 2000). 
Com relação à temperatura de $\pm 4^{\circ} \mathrm{C}$, esta foi utilizada para simular as condições em que geralmente estas bebidas são ingeridas. De acordo com as leis da cinética química, o aumento da temperatura é diretamente proporcional à velocidade da reação. Dessa forma, a erosão torna-se mais grave com o aumento da temperatura (Barbour et al., 2006). Em estudo realizado por West et al., 2000, verificou-se que o aumento da temperatura de $5^{\circ} \mathrm{C}$ a $60^{\circ} \mathrm{C}$ aumentou de forma significante a perda tecidual de esmalte e dentina. A maioria das investigações em relação ao potencial erosivo de bebidas ácidas é comumente realizada em temperatura ambiente ou a $37^{\circ} \mathrm{C}$. Porém, a maioria das bebidas é ingerida quente ou gelada. Ainda não há padronização para as temperaturas e, vale ressaltar que, por existir variação de temperatura nas diferentes partes do mundo, torna-se necessária a padronização desta nas pesquisas deste gênero.

Foi utilizada uma garrafa de $600 \mathrm{~mL}$ de bebida à base de limão (tampa rosqueável) por dia. Não houve reaproveitamento desta bebida sendo que a cada ciclo de imersão/agitação a solução foi descartada, de acordo com a metodologia proposta por Hunter et al., (2003), garantindo um nível consistente de gás carbônico na bebida.

Zero e Lussi, 2005, relataram que as bebidas gaseificadas são potencialmente mais erosivas que as soluções não gaseificadas, uma vez que está presente em sua composição o ácido carbônico.

Utilizou-se neste estudo a microdureza Knoop com carga de 50gf. Segundo Zero et al., 1990 esta carga é suficiente para detectar pequenas alterações na superfície do esmalte, sendo também utilizada nos trabalhos de Lussi et al., 1993, Lussi et al., 1995; Lussi et al., 2000). Vários métodos têm sido utilizados para avaliar a erosão dentária, entre eles a microrradiografia, que determina a profundidade da lesão por avaliar a perda mineral interna e da superfície determinando a profundidade da lesão (Margolis et al., 1999; Amaechi e Higham, 2001); a perfilometria, método sensitivo que traça o perfil do espécime em um gráfico (Hughes et al., 2000; Attin et al.,2003); o método ultra-sônico , no qual os 
espécimes são colocados no ultra-som por 5 segundos afim de remover o esmalte desmineralizado para posterior análise da diferença antes do utra-som e o perfil da erosão (Eisenburger et al., 2000); o método da permeabilidade do iodo capaz de detectar pequenas alterações em toda a superfície do espécime por ser sensível a estruturas irregulares, mostrando alterações na porosidade, sem afetar de forma irreversível a superfície testada (Lussi et al., 1993); o sistema de nanoendentação ou ultra-micro-endentação, instrumento sensível à profundidade, capaz de detectar estágios iniciais da dissolução do esmalte (Mahoney et al., 2003; Barbour et al., 2003; Lippert et al., 2004). Uma das vantagens da análise da erosão do esmalte pelo método da microdureza utilizado nesta pesquisa é o baixo custo, comparado à nanoendentação além de ser um método fácil e de rápida execução (Barbour e Rees, 2004).

A maioria dos trabalhos que quantifica a capacidade erosiva das bebidas geralmente avalia a microdureza superficial. Neste estudo, no entanto, a microdureza profunda foi analisada resultando em dados complementares à avaliação da microdureza superficial. A finalidade de realizar medidas de microdureza em profundidade foi a de verificar a capacidade de penetração das bebidas no esmalte. Na literatura, são escassos os trabalhos que avaliam a microdureza na subsuperfície do esmalte. Larsen e Nyvad, 1999, após realizar desafios ácidos, avaliaram a microdureza em profundidade em esmalte de dentes permanentes, porém sem uma padronização da distância das superfícies desgastadas pela erosão. Observaram que ao contrário da água mineral, os refrigerantes à base de limão e o suco de laranja não mostraram um limite definido de profundidade. Amaechi e Higham (2001) observaram em microrradiografia, que a exposição durante 01 hora em suco de laranja foi capaz de produzir uma lesão de erosão no esmalte, caracterizada por uma cratera rasa e desmineralização da subsuperfície, atingindo $75 \mu \mathrm{m}$ de profundidade. Eisenburger et al., 2000, avaliou a desmineralização subsuperficial do esmalte através do método ultrasônico verificando que lesões erosivas formadas por exposição por um período de 30 
minutos à uma hora alcançaram, aproximadamente, $1 \mu \mathrm{m}$ de profundidade, enquanto as lesões expostas a desafios ácidos de 2 a 4 horas atingiam de 2-4 $\mu$ m de profundidade. Desta forma, existe atuação em profundidade de uma solução potencialmente erosiva e este estudo visou verificar o grau de atuação das bebidas avaliadas.

Após os 60 dias de imersões, as áreas do esmalte previamente submetidas aos testes de microdureza superficial foram seccionadas longitudinalmente. Observou-se na interação dos fatores solução X profundidade, em que apenas na profundidade de $300 \mu \mathrm{m}$ é que ocorreu semelhança entre as quatro soluções estudadas. Este fato demonstra a grande capacidade de penetração destas substâncias no esmalte de dentes decíduos. Comparando as soluções estudadas, o grupo do Sprite ${ }^{\circledR}(117,98 \mathrm{KHN})$ promoveu os menores valores de microdureza nas profundidades de 30 a $120 \mu \mathrm{m}$, seguido pelo Kapo ${ }^{\circledR}$ morango $(157,27 \mathrm{KHN})$, que afetou a subsuperfície do esmalte até $200 \mu m$.

Comparando estes resultados com os dados de Torres, 2005, em um estudo semelhante, no qual avaliou o potencial erosivo de uma bebida à base de cola e um suco de laranja à base de soja em dentes decíduos, foi verificado que a alteração em profundidade para as bebidas analisadas foi evidente até $150 \mu \mathrm{m}$. Desta forma, as soluções utilizadas, no presente estudo, foram mais agressivas, atingindo o esmalte em maiores profundidades.

Além da avaliação da microdureza superficial e profunda, a microscopia eletrônica de varredura (MEV) é um método qualitativo que visa complementar os resultados do teste de microdureza, devendo ser utilizado em associação aos métodos quantitativos (Lussi et al., 1993; Johansson et al., 2001; Eisenburger et al., 2004). Grando et al., 1996, e Torres (2005) após análise da superfície do esmalte de dentes decíduos imersos em diferentes bebidas, observaram através de microscopia eletrônica de varredura, que a desmineralização dos prismas de esmalte foi crescente com o aumento do tempo de exposição. 
Neste estudo, após análise em microscopia eletrônica de varredura, foi constatada a ocorrência de um processo de desmineralização gradual da superfície do esmalte, demonstrando que o ácido cítrico presente nas soluções utilizadas ataca mais a porção interprismática, estando de acordo com a literatura. Além disso, aos 60 dias de exposição, foi observada uma destruição generalizada nos espécimes de todos os grupos exceto o da saliva, principalmente nos espécimes do grupo do Sprite ${ }^{\circledR}$, onde a superfície do esmalte apresentou nítida perda de estrutura, sendo esta planificada e desgastada, ou formando cavidades diferenciadas como nos espécimes do grupo do Kapo ${ }^{\circledR}$ morango. Em relação ao $\operatorname{Ades}^{\circledR}$ maçã, a desmineralização aos 60 dias de imersão não atingiu áreas específicas. Essa análise qualitativa foi compatível com os resultados dos testes de microdureza, que demonstraram que o Sprite ${ }^{\circledR}$ atingiu o esmalte de maneira mais agressiva em relação às outras soluções utilizadas.

Este estudo possui importância clínica sob a ótica preventiva, pois se um diagnóstico adequado for realizado durante a dentição decídua, será possível desenvolver uma estratégia preventiva para a fase posterior de dentição permanente. No entanto, uma vez que a erosão neste experimento foi induzida in vitro, os resultados não devem ser extrapolados para a situação clínica, onde o potencial erosivo de um ácido dependerá também da situação in vivo e será levada em consideração a susceptibilidade individual.

O desenvolvimento constante de novos estudos é necessário a fim de difundir e ampliar os conhecimentos na área. 


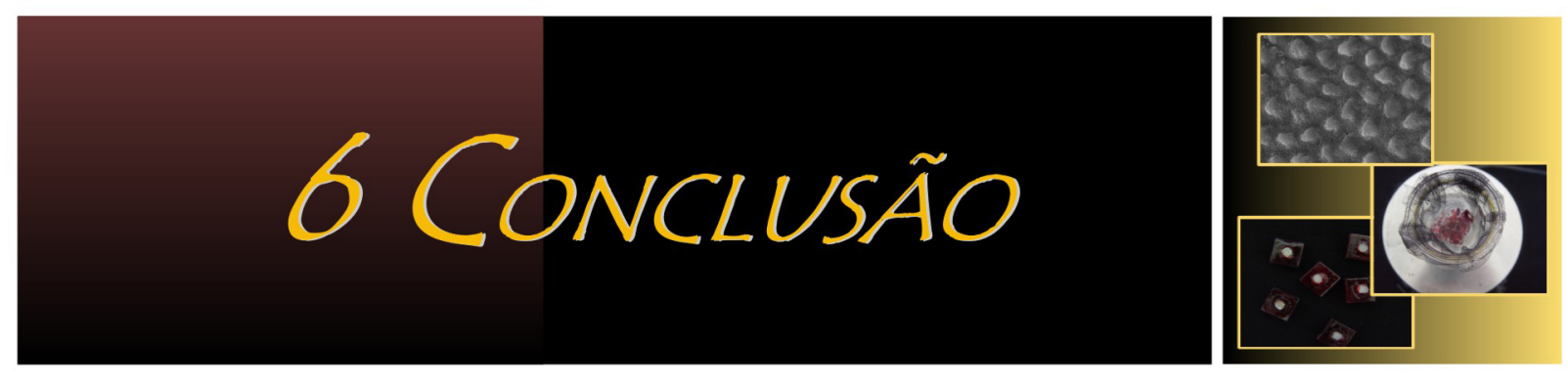




\section{ConClusÃo}

Após análise dos resultados obtidos neste estudo, pôde-se concluir que:

- As três bebidas avaliadas neste estudo alteraram negativamente a microdureza superficial e profunda do esmalte dos dentes decíduos.

- Quanto maior o tempo de exposição a essas bebidas, maior foi a alteração na microdureza do esmalte, o que foi confirmado pela microscopia eletrônica de varredura.

- A alteração em profundidade para as bebidas analisadas foi evidente até $200 \mu \mathrm{m}$, sendo que o Sprite ${ }^{\circledR}$, alterou o esmalte de maneira mais intensa seguido pelo Kapo ${ }^{\circledR}$ morango e Ades Maçã. 
REFEREANCIAS

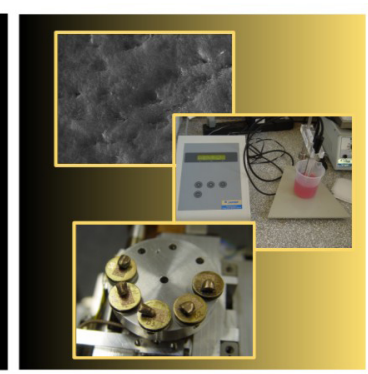




\section{REFERÊNCIAS*}

1. Addy $M$, Shellis RP. Interaction between attrition, abrasion and erosion in tooth wear. Monogr Oral Sci 2006; 20:17-31.

2. Al-Dlaigan $\mathrm{YH}$, Shaw I, Smith A. Dental erosion in a group of British 14-year-old, school children. Part I: prevalence and influence of differing socioeconomic backgrounds. $\mathrm{Br}$ Dent J 2001; 190:145-9.

3. Amaechi BT, Higham SM, Edgar WM. Factors influencing the development of dental erosion in vitro: enamel type, temperature and exposure time. J Oral Rehabil 1999; 26: 624-30.

4. Amaechi BT, Higham SM. $\mathrm{n}$ vitro remineralisation of eroded enamel lesions by saliva. J Dent. 2001 Jul;29(5):371-6.

5. Anderson $P$, Levinkind $M$, Elliot JC. Scanning microradiographic studies of rates of in vitro desmineralization in human and bovine dental enamel. Arch Oral Biol 1999; 43:649-56.

6. Asher C, Read MJ. Early enamel erosion in children associated with the excessive consumption of citric acid. Br Dent J 1987; 162:384-7.

7. Attin T, Meyer K, Hellwig E, Buchalla W, Lennon AM. Effect of mineral supplements to citric acid on enamel erosion. Arch Oral Biol. 2003, 48(11):753-9.

8. Barbour ME, Parker DM, Allen GC, Jandt KD. Human enamel dissolution in citric acid as a function of pHin the range $2.3<$ or $=\mathrm{pH}<$ or $=6.30-$ a nanoedentation study. Eur $\mathrm{J}$ Oral Sci. 2003; 111(3):258-62.

9. Barbour ME, Rees JS. The laboratory assessment of enamel erosion: a review. J Dent 2004; 32:591-602.

10. Barbour ME, Finke M, Parker DM, Hughes JA, Allen GC, Addy M. The relationship between enamel softening and erosion caused by soft drinks at a range of temperatures. J Dent. 2006; 34(3):207-13.

11. Barllet DW, Coward PY, Nikkah C, Wilson RF. The prevalence of tooth wear in a cluster sample of adolescent schoolchildren and its relationship with potencial explanatory factors. Br Dent J 1998; 184:125.

12. Bartlett DW, Shah P. A critical review of non-carious cervical (wear) lesions and the role of abfraction, erosion, and abrasion. J Dent Res. 2006; 85(4):306-12.

13. Bjovatn K. Antibiotic compounds and enameldemineralization. An in vitro study. Acta Odontol Scand 1982; 40:341-52.

\footnotetext{
*Normas internas do Programa de Pós-Graduação em Odontopediatria da FORP/USP(2003), de acordo com o International Committee of Medical Journal Editors. Uniform requiriments for manuscripts submited by Medical Journal, 1997. Disponivel em : <http//www.mja.com.au/public/information/uniform.htm/>. Acesso em 16 de junho de 2003, e com a Associação Brasileira de Normas Técnicas - NBR 6023,ago.2002.
} 
14. Brown CJ, Smith G, Shaw L, Parry J, Smith AJ. The erosive potencial of flavoured sparkling water drinks. Int J Pediatr Dent 2007; 17 (2): 86-91.

15. Deery C, Wagner ML, Longbotton C, Simon R, Nugent ZJ. The prevalence of dental erosion in a United States and a United Kingdom sample of adolescents. Pediatr Dent 2000; 22: 505-10.

16. Eccles JD. Tooth surface loss from abrasion, attrition and erosin. Dent Update 1982; 9:373-81.

17. Eisenburger $M$, Hughes J, West NX, Jandt KD, Addy M. Ultrasonication as a method to study enamel demineralisation during acid erosion. Caries Res. 2000; 34(4):289-94.

18. Eisenburger $M$, Addy $M$, Hughes JA, Shellis RP. Effect of time on the remineralisation of enamel by synthetic saliva after citric acid erosion. Caries Res. 2001;35(3):211-5

19. Eisenburger M, Shellis RP, Addy M. Scanning electon microscopy of softened enamel. Caries Res. 2004; 38: 67-74.

20. Ganss C, Klimek J, Giese K. dental erosion in children and adolescents - a cross sectional and longitudinal investigation using study models. Community Dent Oral Epidemiol 2001; 29: 264-71.

21. Gimalia I, Steinberg D, Grobler S, Gedalia I. The effects of propolis exposure on microhardness of human enamel in vitro. J Oral Rehabil 1999; 26: 941-3.

22. Grando L], Tames DR, Cardoso AC, Gabilan NH. In vitro study of enamel erosion caused by soft drinks and lemon juice in deciduous teeth analysed by stereomicroscopy and scanning electron microscopy. Caries Res 1996; 30(5):373-8.

23. Grenby TH. Lessening dental erosive potential by product modification. Eur J Oral Sci. $1996 ; 104(2): 221-8$.

24. Grobler e Van der Horst G. Biochemical analysis of various cool drinks with regard to enamel erosion, de and remineralization. J Dent Assoc S Afr 1982; 37:681-4

25. Grobler, SR, du Toit IJ, bassoon NJ. The effect of honey on human tooth enamel in vitro observed by electron microscopy and microhardness measurements. Arch Oral Biol 1994; 39 (2) 147-153.

26. Hall AF, Sadler JP, Strang R, de Josselin de Jong E, Foye RH, Creanor SL. Application of transverse microradiography for measurement of mineral loss by acid erosion. Adv Dent Res 1997; 11:420-5.

27. Hannig $M$, Döbert $A$, Stigler $R$, Müller $U$, Prokhorova SA. Initial salivary pellicle formation on solid substrates studied by AFM. J Nanosci Nanotechnol 2004, 4(5):532-8.

28. Hara AT, Lussi A, Zero DT. Biological factors. Monogr Oral Sci. 2006; 20:88-99.

29. Holbrook WP, Arnadottir IB, Kay EJ. Prevention. Part 3: prevention of tooth wear. $\mathrm{Br}$ Dent J 2003;195:75-81 
30. Holloway PJ, Mellamby MRJCS. Fruit drinks and tooth erosion. Br dent 1959;104:305:9.

31. Hooper S, Hughes J, Parker D, Finke M, Newcombe RG, Addy M, West N. A clinical study in situ to assess the effect of a food approved polymer on the erosion potential of drinks. J Dent. 2007; 35(6):541-6.

32. Hughes JA, West NX, Parker DM, Newcombe RG, Addy M. Development and evaluation of a low erosive blackcurrant juice drink in vitro and in situ. 1. Comparison with orange juice. J Dent 1999; 27: 285-9.

33. Hughes JA, West NX, Parker DM, van den Braak MH, Addy M. Effects of $\mathrm{pH}$ and concentration of citric, malic and latic acids on enamel in vitro. Journal of Dentistry 2000; 28:147-152.

34. Hunter, $M L$ et al. Erosion of deciduous and permanent dental hard tissue in the oral environment. J Dent; 2000: 28(4) 257-263.

35. Hunter ML, Hughes JA, Parker DM, West NX, Newcombe RG, Addy M. Development of low erosive carbonated fruit drinks. 1. Evaluation of two experimental orange drinks in vitro and in situ. J Dent. 2003; 31(4):253-60.

36. Imfeld T. dental erososion. Definition, classification and links. Eur J Oral Sci 1996; 104:151-5.

37. Järvnen VK, Rytomaa I, Heinonen OP. Risk factors in dental erosion. J.Dent Res 1991; 70: $942-7$.

38. Järvnen V, Meurman JH, Hyvarinen $\mathrm{H}$, Rytomaa I, Murtomaa $\mathrm{H}$. Dental erosion and upper gastrointestinal disorders. Oral Surg Oral Med Oral Pathol 1988; 65: 298-303.

39. Johansson AK, Sorvari R, Birkhed D, Meurman JH. Dental Erosion in deciduous teeth - an in vivo and in vitro study. J Dent 2001; 29: 333-40.

40. Kitchens M, Owens BM. Effect of carbonated beverages, coffee, sports and high energy drinks, and bottled water on the in vitro erosion characteristics of dental enamel. J Clin Pediatr Dent 2007; 31(3):153-9.

41. Larsen MJ, Nyvad B. Enamel erosion by some soft drinks and orange juices relative to their $\mathrm{pH}$, buffering effect and contents of calcium phosphate. Caries Res 1999, 33: 8187.

42. Larsen MJ. Prevention by means of fluoride of enamel erosion as caused by soft drinks and orange juice. Caries Res 2001; 35:229-234.

43. Larsen $\mathrm{MJ}$, Richards $\mathrm{A}$. Fluoride is unable to reduce dental erosion from soft drinks. Caries Res 2002; 36(1):75-80.

44. Lewinstein I, Ofek L, Gedalia I. Enamel reharding by soft cheeses. Am j Dent 1993; 6; 46-8.

45. Lendenmann U, Grogan J, Oppenheim FG. Saliva and dental pellicle--a review. Adv Dent Res. 2000; 14:22-8. 
46. Lippert F, Parker DM, jandt KD. Susceptibility of deciduous and permanent enamel to dietary acid induced erosion studied with atomic force microscopy nanoindentation. Eur J Oral Sci 2004; 112:61-6

47. Litonjua LA, Andreana S, Bush PJ, Cohen RE. Tooth wear: attrition, erosion, and abrasion. Quintessence Int 2003; 34: 435-46.

48. Litonjua LA, Andreana S, Cohen RE. Toothbrush abrasions and noncarious cervical lesions: evolving concepts. Compend Contin Educ Dent 2005; 26(11):767-8.

49. Lussi A., Jaeggi T, Scharer S. The influence of different factors on in vitro enamel erosion. Caries Res 1993; 27: 387-93.

50. Lussi A., Jaeggi T, Jaeggi-Scharer S. Prediction of the erosive potencial of some beverages. Caries Res 1995; 29: 349-54.

51. Lussi, A. et al. A comparison of the erosive potencial of different beverages in primary and permanent teeth using an in vitro model. Eur J Oral Sci 2000; 108: 2.110-114.

52. Lussi A, Kohler $N$, Zero $D$, The hole of diet in the etiology of dental erosion. Caries Res; 38 Suppl 1: 34-44, 2004.

53. Magalhães AC, Rios D, Delbem ACB, Buzalaf MAR, Machado MAAM. Influence of fluoride dentifrice on brushing abrasion of eroded human enamel: na in situ/ ex vivo study. Caries Res 2007; 41:47-49.

54. Mahoney E, Beattie J, Swain M, Kilpatrick N. Preliminary in vitro assessment of erosive potential using the ultra-micro-indentation system. Caries Res 2003; 37:218-24.

55. Maia LC, Modesto A. Análise comparativa, ao microscópio eletrônico de varredura de esmalte bovino exposto a diferentes soluções ácidas. Um estudo in vitro. Ver Odontol Univ São Paulo 1996; 10:161-168.

56. Margolis HC, Zhang YP, Lee CY, Kent RL Jr, Moreno EC Kinetics of enamel demineralization in vitro. J Dent Res 1999; 78: 1326-35.

57. Maupomé G, Diez de-Bonilla J, Torres Villasenor G, Andrade-Delegado LC, Castano VM. In vitro quantitative assessment of enamel microhardness after exposure to eroding immersion in a cola drink. Caries Res 1998; 32:148-53.

58. Maupomé G, Aguilar-Avila M, Medrano-Ugalde $\mathrm{H}$, Borges -Yanez A., In vitro quantitative assesment of enamel with early salivary pellicles after exposure to na eroding cola drink. Caries Res 1999; 33:140-7.

59. Meurman JH, Torkko H, Hirvonen J, Koskinen J, Rytömaa I. Application of a new mechanical properties microprobe to study hardness of eroded bovine enamel in vitro. : Scand J Dent Res 1990; 98(6):568-70.

60. Meurman JH, Frank RM. Scanning electron microscopc study of the effect of salivary pellicle on enamel erosion. Caries Res 1991; 25:1-6. 
61. Milosevic A, Slades PD, The orodental status of anorexis and bulimics. Br Dent J 1989; 167:66-70.

62. Milosevic A, Brodie DA, Slade PD, Dental erosion, oral hygiene, and nutritio in eating disorders. Int J Eat Disord 1997; 21:195-9

63. Moazzes R, Bartlett $D$, Anggiansah A. Dental erosion, gastro-oesophageal reflux disease and saliva: how are they related? J Dent 2004; 32:489-94.

64. Newbrun E. Dental caries in the future: a global view. Proc Finn Dent Soc 1992; 88:15561.

65. Marthaler TM. The prevalence of dental caries in Europe. Caries Res 1996; 30:237-55.

66. Morgan KJ, Stults VJ, Stampley GL. Soft drink consumption patterns of the U.S. population. J Am Diet Assoc 1985; 85:352-354.

67. Peterson G, Brathall D. The caries decline: a review of reviews. Europ J Oral Sci 1996; 104: 436-43.

68. Pontefract $\mathrm{H}$, Hughes J, Kempt K, Yates R, Newcombe RG, Addy M. The erosive effects of some mouthrinses on enamel: A study in situ. J Clin Periodontol 2001; 28:319-324.

69. Pretty IA,Edgar WM, Highman SM. The erosive potential of commercially available mothrinses on enamel as measured by QuantitativeLight Induced Fluorecence. J Dent 2003; 31:313-9.

70. Rees JS. The biomechanics of abfraction. Proc Inst Mech Eng [H]. 2006; 220(1):69-80

71. Rytomaa I, Meurman JH, Koskinem J, et al., In vitro erosion of bovine enamel caused by acidic drinks and other foodstuffs. Scand J Dent res 1988; 96:324-333.

72. Sela MO, Shapira L, Grizim I, Lewinstein I, Steiberg D, Gedalia I, Grobler SR. Effects of honey consumption on enamel microhardness in normal versus xerostomic paciens. J Oral Rehabil 1998; 25:630-4.

73. Seow WK, Thong KM. Erosive effects of common beverages on extracted premolar teeth. Australian Dental Journal 2005; 50(3): 173-178.

74. Shaw L, Smith A. Erosion in children: an increasing clinical problem. Dental Update $1994 ; 21: 263-6$.

75. Shellis RP, Finke M, Eisenburger M, Parker DM, Addy M. Relationship between enamel erosion and liquid flow rate. Eur J Oral Sci. 2005; 113(3):232-8.

76. Scheper WA, van Nieuw Amerongen A, Eijkman MA. Oral conditions in swimmers Ned Tijdschr Tandheelkd. 2005;112(4):147-8.

77. Sorvari R. Effects of various sport drink modifications on dental caries and erosion in rats with conoled eating and drinking pattern. Proc FinnDent Soc 1989; 85:13-20. 
78. Torres CP. Microdureza do Esmalte de Dentes Decíduos - Influência de bebidas, em função do tempo de exposição. Avaliação In vitro (dissertação). Ribeirão Preto: FORP Univ. de São Paulo; 2005.

79. Tylenda, CA et al. Bulimia nervosa: its effects on salivary chemistry. J Am Dent Assoc, $1991 ; 122,37-41$.

80. Touyz, L ZG. The acidity $(\mathrm{pH})$ and buffering capacity of Canadian fruit juice and dental implications. J Can Dent Assoc. 1994; 60( 5) 454-458.

81. Van Eygen I, Vannet BV, Wehrbein H. Influence of a soft drink with low pH on enamel surfaces: an in vitro study. Am J Orthod Dentofacial Orthop. 2005, 128(3):372-7.

82. Van Herpen $\mathrm{BP}$, Arends $\mathrm{HL}$. Influence of consumption frequence of filled chocolate products on demineralization of human enamel in vivo. A microhardness and micrographic investigation. Caries Res 1986; 20:529-33.

83. Watari F. In situ etching observation of human teeth in acid agent by atomic force microscopy. J Eletr Microscopy 1999; 48:537-44.

84. West NX, Hughes JA, Parker DM, Newcombe RG, Addy M. Development and evaluation of a low erosive blackcurrant juice drink. 2. Comparision with a convencional blackcurrant juice and orange juice. J Dent 1999; 27:341-4.

85. West NX, Hughes JA, Addy M. Erosion of dentine and enamel in vitro by dietary acids: the effect of temperature, acid character, concentration and exposure time. J Oral Rehabil. 2000; 27(10):875-80.

86. West NX, Hughes JA, Parker DM, Moohan M, Addy M. Development of a low erosive carbonated fruit drinks. 2. Evaluation of an experimental carbonated blackcurrant drink compared to a convencional blackcurrant drink. J Dent 2003; 31:361-5.

87. Wilson PR, Beynon AD. Mineralization differences between human deciduous and permanent enamel measured by quantitative microradiography. Arch Oral Biol 1989; 34: 85-8.

88. Yu H, Oho T, Xu LX. Effects of several tea components on acid resistance of human tooth enamel. J Dent 1995; 23: 101-5.

89. Zantner C, Nils BS, Konrad N, Andrej MK. Surface microhardness of enamel after different home bleaching procedures. Dental Materials 2007; 23: 243-250.

90. Zero DT, Rahbek I, FU J, Proskin HM, Featherstone JDB: Comparison of the iodide permeability test, the surface microhardness test, and mineral dissolution of bovine enamel following acid challenge. Caries Res 1990, 24: 181-188.

91. Zero DT, Lussi A. Erosion-chemical and biological factors of importance to the dental practitioner. Int Dent J 2005; 55(4 Suppl 1):285-90.

92. Zipkin J, McClure FJ. Salivary citrate and dental erosion. J Dent Res 1949; 28: 613-26. 


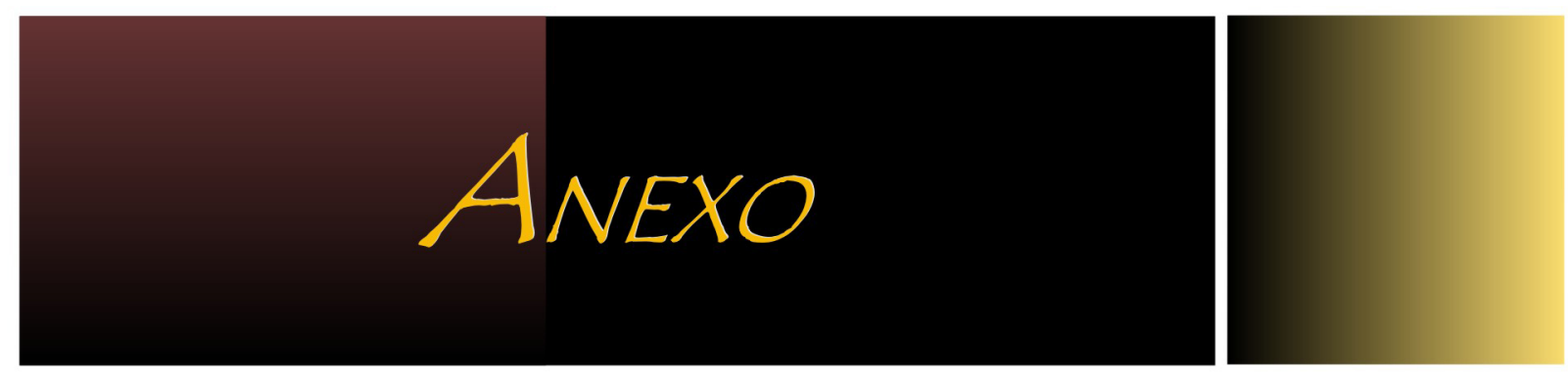




\section{Anexo A- Aprovação do Comitê de Ética}

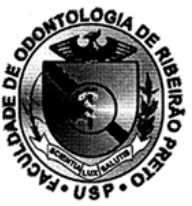

OF.CEP/194/FORP/27062007

Prezado(a) Professor(a),

\author{
UNIVERSIDAD.E DE SÃO PAULO \\ FACULDADE DE ODONTOLOGİ DE RIBEIRÃO PRETO \\ COMITÊ DE ÉTICA EM PESQUISA \\ Avenida do Café, s/n ${ }^{\circ}$ - Telefone: (016) 3602-3963 \\ 14040-904 - Ribeirão Preto - SP - Brasil \\ Fax: (016) 3633-0999
}

Ref.: Processo n. 2007.1.458.58.7

Caae n. 0026.0.138.000-07

De ordem da Senhora Coordenadora do Comitê de Ética em Pesquisa desta Faculdade, informamos que o referido Comitê, em sua 79a Sessão, realizada no dia 21 de junho de 2007, aprovou o Projeto de Pesquisa envolvendo seres humanos intitulado: "Influência de bebidas ingeridas rotineiramente por crianças na microdureza do esmalte de dentes decíduos: Avaliação in vitro", a ser desenvolvido por Vossa Senhoria, na Faculdade de Odontologia de Ribeirão Preto, devendo o atestado para publicação final, ser expedido pelo Comitê de Ética em Pesquisa, após a entrega e aprovação do Relatório Final pelo referido Comitê.

$\mathrm{Na}$ oportunidade, esclarecemos que o Relatório Final deverá ser encaminhado à Secretaria do Comitê de Ética em Pesquisa até o dia 30 de janeiro de 2008, conforme modelo que se encontra no site da FORP/USP (link: Colegiados e Comissões - Comitê de Ética em Pesquisa - Formulários do Pesquisador para entrega dos Relatórios Parcial ou Final).

Atenciosamente,

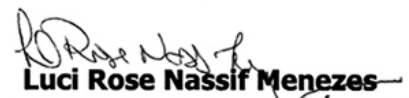

Secretária do "ad hoc"do Comitê de Ética em Pesquisa

Profa. Dra. Maria Cristina Borsatto

Professora Associada do Departamento de Clínica Infantil, Odontologia Preventiva e Social FORP/USP

LRNM/bgep 


\section{AUTORIZAÇÃO PARA REPRODUÇÃO}

Autorizo a reprodução e/ou divulgação total ou parcial da presente obra, por qualquer meio convencional ou eletrônico, desde que citada a fonte.

Ribeirão Preto/Julho de 2007 Avenida do Café s/n - CEP 14040-904 e-mail: soraya@forp.usp.br 